\title{
Hagen Fleischer
}

\section{Griechenland}

Die jüdische Präsenz im griechischen Raum ist älter, facettenreicher und - bis zum Massenmord im Rahmen der ${ }_{n}$ Endlösung ${ }^{1}{ }^{1}$ - vielgestaltiger als in fast allen anderen Lāndern Europas. Diese Vielfalt findet gewisse Entsprechungen in der unterschiedlich ausgebildeten Fähigkeit, der furchtbarsten Bedrohung in der vielbewegten eigenen Geschichte, dem nationalsozialistischen Moloch, zu begegnen; dementsprechend sind auch die regional stark differierenden Uberlebensquoten nicht allein mit irgendwelchen Zufälligkeiten zu erklären.

1 Von der einschlïgigen Literatur ist an erster Stelle das kollektive Standandwerk zu nennen: Michael Molho u.2. In Memoriam. Hommage aux victimes juives des nazis en Grice. Bd. I/II, Saloniki 1948/49; Bd. III, Buenos Aires 1953. (Molho verfafte den gröbten Teil des 1. sowie den - ausschlieflich vom Friedhof in Salonikj handelnden - 3. Band, wohingegen der 2. Band von Joseph Nehama stammt) 1976 gab die Jüdische Gemeinde eine einbändige griechische Ubersetzung hernus, wobei der integrierte Bd. II eine Anzahl Verbesserungen und Erweiterungen von Nehama enthalt. (Israilitiki Koinotis Thesselonikis, In Memoriam, Saloniki 1976.) In der vorliegenden Untersuchung wird für die Ereignisse von Selonilki (Bd. I) die leichter zugïngliche französische Originalausgabe benutzt, für Bd. II indessen dje verbesserte griechische Version.

Unentbehrlich für die Tragödie von Saloniki ist auch: I $\Lambda$ Matarsso, Ki'omos oloi tous den pethanan, Athen 1948. Von nichtgriechischen Quellen sind wichtig: Cecil Roth, The Lest Days of Jewish Salonice, in: Commentary X:1, Juli 1950, S. 49-55; die Studie von Danuta Czech, Deportation und Vemichtung der griechischen Juden im KL Auschwitz, in: Hefte von Auschwitz 11 (1970), S. 5-37. Femer natürlich die Holocaust${ }_{n}$ Klassiker", die jeweils auch Griechenland-Kapitel enthalten, insbesondere Gerald Reitlinger, Die Endlösung, Berlin 19614; Raul Hilberg, Die Vernichtung der europäischen Juden. Die Gesamtgeschichte des Holocaust, Berlin 1982; sowie Martin Gilbert, Endlösung. Die Vertreibung und Vemichtung der Juden. Ein Atlas, Reinbek 1982. - In der DDR erschien der - trotz verschiedener Simplifizierungen - bis dahin vielleicht beste Ubersichtsartikel: Rainer Eckert, Die Verfolgung der griechischen Juden im deutschen Okkupationsgebiet Saloniki- $\lambda_{g}$ ais vom April 1941 bis zum Abschluß der Deportationen im August 1943, in: Bulletin des Arbeitskreises, Zweiter Weltkrieg " (1986), S. 41-69.

In seiner nützlichen bibliographischen Ubersicht bednuert Philip Friedman (The Jews of Greece during the Second World War. The Joshua Starr Memorial Volume, New York 1953, S. 241-248) zu Recht die „Durttigkeit" der historiographischen Bearbeitung des Schicksals der griechischen Juden: „It must be said that it is one of the most unexplored areas of the Jewish Catastrophe." Seitdem hat sich kaum etwas geandert: weiterhin gilt der Forschungsstand von 1950, die neueren Publikationen stützen sich unkritisch auf die Pioniere Matarasso, Molho und Nehama; die in unregelmäßigen Abständen vom Jüdischen Zentralrat herausgegebenen Broschüren etc. machen hier keine Ausnahme. Kaum neues Material bringt auch der dem Vf. freundlicherweise schon als Manuskript überlassene Ubersichtsartikel von Steven Bowman. Jews in War-Time Greece (inzwischen veröffentlicht in: Jewish Social Studies 48 (1986), S. 45-62), obwohl der Autor des Aufsatzes zu den bestinformierten gehört und Zugang zu hebräischen Quellen hat. Vgl. seine Bibliographie unter dem gleichen Titel in: J.O. Intrides (Hrsg.) Greece in the 1940s, Hannover 1981, Bd. IL, S. 81-94. Genannt werden muß hier noch die weit ambitiösere Bibliographie von Robert Attal, Les Juits de Grèce de l'expulsion d'Espagne à nos jours, Jerusalem 1984.

Auch die Verantwortichen des Yad Vashem-Archivs sind sich dieses fortwährenden Mankos bewußt (Dr. Herbert Rosenknnz, Brief, 31.7.1984). Der VI. hat in dieser Untersuchung außer den genannten Werken zahlreiche autobiographische Berichte, lokalhistorische Studien, wie auch einen beträchtlichen Teil der Kriegs- (auch Resistance-) und Nachkriegspresse ausgewertet, femer die deutschen, britischen und amerikanischen Weltkriegsakten sowie die umfangreichen Ermittlungsunterlagen deutscher Stantsanwaltschaften (v.a die 17 Bände der Generalstantsanwaltschaft beim Londgericht Berlin - 3 P(K) Js 10/60 gegen M. Merten u.a). Schärfere Konturen erhielt dieses Bild wiederholt durch Interviews mit Uberlebenden. 
Die Anfänge hebräischer Kolonien werden nicht selten bis in die Zeit der Babylonischen Gefangenschaft (586-530 v. C.) zurückdatiert; andere „Nachfahren“ sind überzeugt, daß zumindest bei der Gründung Thessalonikis vor 2300 Jahren Juden zu den ersten Siedlem gehörten. Gesichert ist jedenfalls ein neuer Exodus nach den Makkabäer-Kriegen (166-160 v. C.) - entweder direkt von Palästina-Judāa oder über die aufstrebenden Handelszentren der hellenistischen Welt, Alexandria und Antiochia. Strabo ( 85 v. C.) und insbesondere Paul von Tarsus (ca. 50 n. C.) sind namhafte Zeugen für die mittlerweile lebhafte Ausbreitung der jüdischen Diaspora auf dem Boden des heutigen Griechenlands (Saloniki, Korinth etc.).

Mit relativ geringen Restriktionen entwickeln sich die Gemeinden in den Jahrhunderten der oströmischen/byzantinischen Herrschaft. Der früh aufkommende Terminus „Romanioten " für die jüdische Minderheit deutet bereits auf eine fortgeschrittene Assimilation gegenüber dem griechischen Wirtsvolk ("Romioi ${ }^{4}$ ). Und tatsāchlich übernehmen die meisten der Gemeinden, die sich am Vorabend des Zweiten Weltkriegs einer ungebrochenen Tradition bis zu den Anfängen unserer Zeitrechnung rühmten (loannina, Chalkis, Kerkyra und Zakynthos), das Griechische nicht nur im täglichen Gebrauch, sondem - obgleich mit hebräischen Einmischungen - auch als Kultsprache; mehr nostalgischen Charakter haben die Versuche, die altehrwürdigen Texte zwar in griechischer Sprache, aber in hebräischer Schrift weiterzugeben.

Unter solchen Vorzeichen schritt die Integration der Romanioten im byzantinischen Kaiserreich weit schneller fort als die ihrer aschkenasischen Glaubensbrüder im Norden; entsprechend selten waren sie massiven Verfolgungen ausgesetzt. Dennoch verbesserten sich ihre allgemeinen Lebensbedingungen wie auch die Aufstiegsmöglichkeiten augenfällig mit der osmanischen Eroberung im 15. Jahrhundert. Die neuen islamischen Herren zeigen eine vergleichsweise große religiōse Toleranz; lediglich die Christen sehen ihre alten Privilegien einschneidend geschmälert, da sie sich plötzlich hinter den Muslim, als zweitklassige ${ }_{n}$ Rajah“, mit den doch mehr oder weniger verachteten Juden - bestenfalls - auf einer Stufe wiederfinden. Letzteren wird nämlich ebenfalls ein eigenes Millet ("Nation") mit religiöser, aber auch weitgehend administrativer Autonomie zuerkannt. Da die meisten Sultane die handelspolitischen und organisatorischen Fähigkeiten ihrer jüdischen Untertanen schātzen - nicht zuletzt als potentielles Gegengewicht gegenüber der Orthodoxie - zögern sie nicht, die Grenzen ihres Reiches zu öffnen, sobald im „christlichen “ Europa eine neue Welle von Judenverfolgungen losbricht. So nehmen die Türken, noch bevor die letzten Bastionen des byzantinischen Staates fallen, aschkenasische Flüchtlinge aus Bayem im 1430 eroberten Saloniki auf.

Das klassische Beispiel für seine Nachfolger gibt aber Bayezid II., als 1492, nach Abschluß der Reconquista, die "Katholischen Majestāten“ Ferdinand und Isabella mit dem Edikt von Granada alle Anhänger der „verderblichen“ mosaischen Religion aus Spanien ( ${ }_{n}$ Sefarad ${ }^{\text {) }}$ ) vertreiben. Im selben Jahr noch lassen sich mindestens 20000 dieser ${ }_{n}$ Sephar(a)dim “ oder „Spaniolen ${ }^{*}$ in der durch Kriegswirren weitgehend entvölkerten Hafenstadt Saloniki nieder. Weitere Wellen iberischer Flüchtlinge folgen - direkt oder nach lāngeren Zwischenaufenthalten in Italien -, und bald sind nicht einmal mehr die im 14. Jahrhundert zwangsgetauften „Marranos“ vor der spanischen Inquisition sicher.

Die an Zahl, Kultur und Dynamik eindeutig überlegenen Neuankömmlinge majo- 
risieren die kleinen romaniotischen und aschkenasischen Gemeinden in Saloniki und stellen dort bald ${ }^{2}$ - relativ wie auch absolut - die größte ethnische Gruppe überhaupt, so daß die Stadt schließlich Beinamen wie „Mutter Israels“, „Klein-Jerusalem “ oder auch „Kōnigin von Israel" erhālt. Eine solche Analogie schließt natürlich die sonst übliche Beschränkung auf Kommerz u.a.. aus. Die Juden sind in allen handwerklichen Sparten tātig, besitzen ein schon traditionelles Monopol auf die Seidenraupenzucht, stellen nicht wenige der besten Drucker des Ostens, aber auch das Proletariat der Tabakarbeiter und Lastenschlepper, so daß noch zu Beginn unseres Jahrhunderts am Sabbath weder Schiffe entladen noch Züge abgefertigt wurden. Eine zeitgenössische deutsche Quelle verwundert sich daher auch, die Sephardim seien „unter den Rassen von Saloniki vielleicht die kräftigste, ein Volk der schwersten Träger und Hafenarbeiter. Bei ihnen ist also nahezu keine physische Degeneration vorhanden, die sonst bei den Juden so hāufig vorkommt. ${ }^{\text {3 }}$

Diese (ab)geschlossene Bevölkerungsgruppe, isoliert in einer fremden, buntgemischten Umwelt, konserviert über Jahrhunderte altkastilische Tradition: Trachten, Sitten, Lieder und insbesondere das Idiom. Das ,Judenspanisch ${ }^{\text {“4 }}$ bewahrt trotz der verschiedensten - meist oberflächlichen - fremdsprachlichen Beimischungen seinen Charakter in einem Ausmaß, daß noch in unserem Jahrhundert Cervantes-Spezialisten zu vergleichenden Sprachstudien nach Saloniki reisten und für den Posten des britischen Konsuls Diplomaten mit Spanischkenntnissen bevorzugt wurden.

Im Vergleich zu „Klein-Jerusalem" bleiben alle anderen Gemeinden in Griechenland drittrangig - gleichgültig, ob sie sich ihre romaniotische Tradition bewahrt haben oder aber dem sephardischen Einfluß erlegen sind (Edime, Rhodos etc.). Einen weiteren Rückgang erleiden sie im Gefolge des griechischen Unabhängigkeitskrieges, der 1821 ausbricht. Da man den Juden „Kollaboration“ mit den verhaßten Türken vorwirft, teilen sie nun zum Teil deren Schicksal - insonderheit die Sephardim, die nicht nur konfessionell ein Fremdkōrper geblieben sind. Die Mehrzahl flieht nach Saloniki bzw. allgemein in die mittel- und nordgriechischen Gebiete, die nach der Konstituierung des neugriechischen Rumpfstaates unter osmanischer Herrschaft verbleiben. Ob-

2 Für weitere Informationen siehe das siebenbändige Standardwerk von Joseph Nehama, Histoire des Isrálites de Salonique. Bezeichnend ist etwa der Titel des 3. Bandes: L'age d'or du Sefaradisme Salonicien (1536-1593), Saloniki 1936. Neu aufgelegt (Paris 1981) wurde das Ubersichtswerk von M. Franco, Essai sur l'Histoire des Israélites de l'Empire Ottoman depuis les Otigines jusqu'à nos jours, Konstantinopel 1897. Wertvolle Aufschlüsse gibt auch der Artikel von Paul Dumont, The Social Structure of the Jewish Community of Salonica at the End of the Nineteenth Century, Southeastem Europe/L'Europe du Sud-Est, 5 Pt. 2 (1979), S. 33-72.

3 Dr. A. Petermanns Mitteilungen aus Justus Perthes' Geographischer Anstalt, XXXIV, H. 162 (1908), S. 358. - Nach Unterlagen des Zionistischen Archivs waren 1912 nur 1500 von 14550 jüdischen Familien in der Lage, Gemeindesteuer zu entrichten. (Rena Molho, I evraiki koinotita tis Thessalonikis kaj i entaxi tis sto elliniko kratos (1912-1919), in: I Thessaloniki meta to 1912, Thessaloniki 1986, S. 288.)

4 In der Sekundärliteratur, selbst jüdischer (Aschkenazim) Provenienz, wird für „Judenspanisch" oft unterschiedslos der Terminus "Ladino" verwendet. Diese Gleichsetzung ist jedoch unrichtig, denn "Ladino" bezeichnet lediglich die künstlich geschaffene, starre liturgische Sprache, entstanden aus mechanischer (Wortzu-Wort-) Ubersetzung der hebrïischen Texte in das Spanisch des 13. Jahrhunderts. Im Gegensatz hierzu steht das Judenspanisch" (Spaniolisch), das lebendige und somit entwicklungsfähige Idiom der Sepharadim; korrekte Synonyme hierfür sind Djudio, Djidio und insbesondere Djudezmo, die urspnünglich nur die jüdische Herkunft des Sprechers herausstreichen (vgl. Jiddisch“ im mittel- und osteuropäischen Raum). Am besten hierzu die Dissertation von Haim Vidal Sephiha, Le Ladino (Judéo-Espagnol Calque). Structure et evolution d'une langue liturgique. 2 Bde, Paris 1979. Siehe auch die kürzere „Bestandsaufnahme“ zur weiteren Problematik vom gleichen Autor: L'agonie des JudéoEspagnols, 2. erw. Aufl, Paris 1979. Hierzu insonderheit S. $14 \mathrm{ff}$. 
wohl sich auch im Süden die Verhāltnisse bald wieder normalisieren und zunehmend Juden zurückkehren oder neu siedeln, erhalten doch beispielsweise die antiken Kolonien von Athen und Patras erst um die Jahrhundertwende wieder den Status einer anerkannten Kultusgemeinde.

Als Griechenland nach dem territorialen Zuwachs im Gefolge der siegreichen Balkankriege die eigene Irredenta in Mazedonien und Thrazien "heimholt", reagiert die mitbetroffene jüdische Minderheit zwiespältig. In den Jahren zuvor hatte sie, insbesondere auch aus wirtschaftlichen Erwägungen, in Konfliktsituationen wie dem griechisch-türkischen Krieg von 1897 kein Hehl aus ihrer Vorliebe für die osmanische Herrschaft gemacht, was erheblichen Mißmut bei der griechischen Bevölkerungsgruppe ausgelöst und nach der Einnahme Salonikis zu verschiedentlichen Übergriffen geführt hatte. Als sich jedoch zeigt, daß nach Vertreibung der Türken auch das jüdischerseits wärmstens begrüßte österreichische Kompromißprojekt einer Internationalisierung der mazedonischen Hauptstadt keinerlei Aussicht auf Verwirklichung hat, findet man sich überraschend schnell mit der neuen Situation ab, umsomehr da zu ihrer freudigen Uberraschung der griechische Ministerprāsident Venizelos eine ausgesprochen philosemitische Politik initiiert.s

Trotz dieser Konsolidierung verstärkt sich schlagartig der bereits seit der Jahrhundertwende beobachtete Trend zur Emigration, dem allerdings mittlerweile nicht nur die stets ein Fremdkörper gebliebenen aschkenasischen Flüchtlinge vor den russischen Pogromen, sondem auch alteingesessene Sephardim folgen. Der verheerende Brand von 1917, der weit über 40000 Juden in Saloniki obdachlos macht, gibt trotz der großzügigen Hilfsaktion der griechischen Regienung neue Anstōße in dieser Richtung. Der entscheidende Einschnitt ist aber die nach dem Scheitern des in Sèvres konzipierten griechischen Smyrna-Abenteuers hereinbrechende „Kleinasiatische Katastrophe ${ }^{\mu}$ von 1922, als allein in Mazedonien Hunderttausende vertriebener Griechen angesiedelt werden und sich aus diesen ein neues Proletariat unter verschärften Wettbewerbsbedingungen rekrutiert. Den flexibleren Neuankömmlingen gelingen erhebliche Einbrüche in fast alle Berufe, die bis dahin von den Juden nahezu monopolartig besetzt gewesen waren. Darüber hinaus werden die etwa 10000 Angehörigen der synkretistischen Sekte der Dönmeh (Maminiken), im 17. Jahrhundert „oberflāchlich“ islamisierte Sephardim, im Rahmen des in Lausanne (1923) vereinbarten Bevölkerungsaustausches in die Türkei umgesiedelt - eine auch von den „Glaubensjuden“ begrüßte Zwangsmaßnahme, deren rettende Auswirkungen sich erst zwanzig Jahre spāter offenbaren werden.

Erste und sichtbarste Konsequenz all dieser Vorgānge ist jedoch der Verlust der traditionellen jüdischen Position als stärkste ethnische Gruppe in Saloniki; dieser Rückgang beschleunigt sich im Laufe der nächsten Jahre, als über 20000 Juden vorzugs-

5 Zum griechisch-jüdischen Verhältnis in jener Umbruchphase vgl. Rena Molho, I evraiki, sowie von der glejchen Autorin: Venizelos and the Jewish Community of Salonika, 1912-1919, in: Journal of the Hellenic Diaspora VIII, 3/4 (Fall-Winter 1986) S. 113-123. Während Venizelos persōnlich auch in der Folgezeit fast stets guten Willen gegenüber der jüdischen Minderheit unter Beweis stellte, herrschten in manchen Schichten seiner ${ }_{n}$ venizelistischen" Anhänger (va. in Flüchtlingskereisen) zumindest latente, innenpolitisch motivierte, antisemitische Vorurteile. Siehe hierzu die deutschen Konsulatsberichte aus Saloniki (Politisches Archiv des Auswàrtigen Amtes) sowie die autoritative Darstellung zur griechischen Zwischenkriegsgeschichte: George Th. Mavrogordatos, Stillbom Republic. Social Coalitions and Party Strategies in Greece, 1922-1936, Berkeley 1983, S. $256 \mathrm{ff}$.; ungerecht hingegen die simplifizierende Kritik an Venizelos in: The American Jewish Committee, Govemments-in-Exile on Jewish Rights, New York 1942, S. 28. 
weise nach Palāstina und Westeuropa emigrieren. 6 Besondere Anziehungskraft übt Paris aus, wo im November 1942 mindestens 5000 Sephardim griechischer Herkunft den braunen Hāschern in die Hānde fallen und den Weg nach Auschwitz antreten werden. ${ }^{7}$

Trotz der genannten Emigrationsschübe stabilisiert sich alles in allem die Lage in Griechenland, und selbst die 1936 von Georg II. und seinem General Ioannis Metaxas etablierte Königsdiktatur zeigt sich in diesem Aspekt - zum Mißfallen der ansonsten dem Regime wohlgesonnenen Berliner Machthaber - von ungewohnter Toleranz: „Die Juden genossen vollkommene Freiheit und führten ein friedliches Leben“, wird ein deutscher "Rassenexperte“ spāter befremdet konstatieren. ${ }^{8}$ Hunderte Verfolgter aus dem weiteren nationalsozialistischen Machtbereich suchen daher hier eine kurzoder längerfristige Zuflucht.9

Doch die Ruhe ist trügerisch. Die italienische Aggression vom 28. Oktober 1940 verwickelt das neutrale Land in den Krieg; als die griechischen Streitkräfte in einem die Weltöffentlichkeit begeisternden Abwehrkampf die Invasoren weit hinter die albanische Grenze zurückwerfen, steht auch die jüdische Minderheit ihren Mann ${ }^{10}$ ebenso, als am 6. April 1941 die deutsche Wehrmacht ihr Gewicht zugunsten des bedrängten Achsenpartners in die Wagschale wirft. Ende April ist die Besetzung des griechischen Festlandes abgeschlossen, einen Monat spāter endet die Luftlandeaktion

6 Die Gründe hierfür sind vielschichtig. Der oft überschätzte Faktor der 1931/33 von antisemitischen Fanatikern inszenierten ephemeren Rassenunruhen waren nur von sekundärer Bedeutung. Die unrühmliche Rolle des Brandstifters - auch im wörtlichen Sinne - hatte damals die kleine, aber aktive Organisation EEE gespielt, die sich auch den deutschen Besatzem als willfähriges Werkzeug zur Verfügung stellen wird.

7 Nehama, Israilitiki Koinotis, S. 253.

8 F. Bachmann, Der Einfluß des Judentums in Griechenland, in: Volk im Osten 4 (1943), S. 60 f.; auch: Die Judenfrage, 15.11.1940, S. $179 \mathrm{ff} . ;$ Messager d'Athènes, 9.9.1936.

$9 \mathrm{~V}$ I. Anm. 28; allein die Zahl der später ermordeten österreichischen Juden wird auf 50 geschätzt (vgl. den Beitrag von J. Moser in diesem Band); die Gesamtzahl war sicherlich weit höher. Der derzeitige (1990) Prisident des Jüdischen Zentralrats in Griechenland, Dr. Löwinger, war übrigens Ende der Dreifligerjahre aus Ungam geflohen, seine Frau aus Osterreich. - Das Sonderkommando Rosenberg resümiert: „Eine wertvolle Hilfe leisteten die griechischen Juden dem Weltjudentum, als es galt, die zahlreichen jüdischen Flüchtlinge aus Mitteleuropa auf legalem oder illegalem Wege nach Palastina zu bringen. In den beiden Verschiffungsplätzen Saloniki und Athen-Pirius befanden sich jüdische Auswandererbüros, die mit englischen und amerikanischen Geldern arbeiteten." (AbschluPbericht über die Tätigkeit des Sondertommandos Rosenberg in Griechenland, 15.11.1941, in: BA, NS 30/75). Tatsächlich sahen die meisten Juden Griechenland nur als Zwischenstation. Der Flüchtlingsstrom gabelte sich dann allerdings. So meldet der SD bereits vor Mussolinis Uberfall aus Athen, $\mathbf{4 0 0}$ deutsche Emigranten (2.T. wohl auch "Arier') seien im Begriff ${ }_{\text {wnach Lissabon }}$ verfrachtet“ zu werden, um dort eine Passage in die USA anzutreten (Chef SiPo/SD VI D4 AZ, 8.8.1940, in: PAAA, Inland II A/B, 295/2); mindestens ebensoviele Juden wollten aber nach Palästina: laut deutschen Informationen erhielten sie die Einreiseerlmubnis der britischen Behörden allerdings nur, sofern sich die wehrähigen Männer zum Heeresdienst verpflichteten. (Chef SiPo/SD DIl 419g, 11.6.1940, in: PAAA, Inland IIg/391). Nicht wenige von ihnen werden allerdings nach dem unglücklichen Ausgang des britischen Griechenlanduntemehmens doch wieder in deutsche Hände fallen: schadenfroh entdecken Kriegsberichterstatter etwa im Gefangenenlager von Korinth Juden aus Worms, Berlin und Wien. (Frankfurter Zeitung, 25.5.1941) - Andere Juden bleiben, freiwillig oder nicht, auf Zypern hängen. Aufschlufreich ist eine Aufstellung der Flüchtlinge in einem Report der Gemeinde von Nikosia an den Colonial Secretary vom 6.5.1941: „Derzeit“ lebten auf der Insel 460 ausländische Juden, darunter 163 aus Osterreich, 92 aus Deutschland, 40 aus Rumanien, 31 aus Polen, 24 aus Ungam, 7 aus der CSSR und 7 Stantenlose. (Dimosio Archeio Kyprou: SAI/670/1941; für diese Information danke ich meinem ehemaligen Studenten Herrn Ch. Pittas.) Bemerkenswerterweise ist in dieser Aufstellung kein einziger Jude mit griechischer Stantsangehörigkeit enthalten!

10 Matarasso, Ki'omos, S. 26; Molho, In Memoriam I, S. 30; - völlig unrealistisch sind die Verlustziffem von Isaac Kabeli, The Resistance of the Greek Jews, in: Yivo Annual of Jewish Social Science 8 (1953) S. 281. Hingegen behauptet die Kollaborationspresse später, die jüdischen Ordensträger hätten sich ihre Auszeichnungen durch Selbstverstūmmelung und ähnliche Tricks erschlichen. (Nea Evropi, 3.3.1943) 
„Merkur“ mit der Einnahme Kretas. Im Rahmen der Mussolini für den ōstlichen Mittelmeerraum zugesicherten „preponderanza“ wird jedoch der größte Teil Griechenlands durch italienische Truppen okkupiert; die eigentlichen Sieger begnügen sich mit einigen Regionen von herausragender strategischer Bedeutung - dazu gehören namentlich das zentralmazedonische Gebiet um Saloniki zwischen Strymon (Struma) und Olymp, einige wichtige Enklaven im ansonsten italienisch besetzten Attika, wie der Hafen Piräus, sowie mehrere Inseln, darunter drei Viertel des schwer erkämpften Kreta.

Bulgarien, das durch seinen Beitritt zum Dreierpakt die deutsche Invasion erst ermöglicht hatte, erhālt ebenfalls einen Anteil an der Beute: die langersehnten Gebiete Thrazien und Ostmazedonien - obgleich Berlin aus mehrgleisigen außenpolitischen Erwägungen vermeidet, der de facto-Annexion seinen offiziellen Segen zu geben. In der Absicht, Konflikte zwischen Sofia und Ankara zu verhindern, wird zudem entlang der türkischen Grenze eine Pufferzone von $2000 \mathrm{~km}^{2}$ um die Stadt Didymotichon (Demotica) von bulgarischer Okkupation ausgespart und der Sicherung durch deutsche Polizeitruppen unterstellt. 11

Diese wechselnden Zustāndigkeiten bewirken, daß die Lage in Griechenland unübersichtlicher ist als in den meisten anderen besetzten Ländern; wenn daher die Judenverfolgungen erst relativ spät einsetzen, so ist diese "Zurückhaltung ${ }^{*}$ nicht nur mit der Absicht zu erklāren, die künftigen Opfer ,in eine trügerische Sicherheit zu wiegen“.12 Vielmehr wünscht das Reichssicherheitshauptamt (RSHA) ein konzentriertes Vorgehen der drei Besatzungsmāchte; bis dahin begnügt man sich auch in der deutschen Zone mit Maßnahmen, die nur selten den Rahmen der individuellen Schikane überschreiten: Schließung der "nicht arischen “ Buchhandlungen und Einstellung der letzten spaniolischen Zeitung „Messagero“, Beschlagnahmung von Häusern, $Z$ wangseinquartierungen sowie einzelne Verhaftungen.

Dennoch erfolgen schon früh erste vorbereitende, aber nicht genügend beachtete

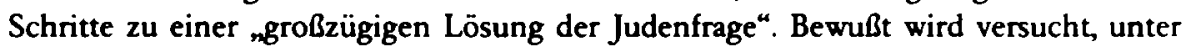
den Griechen eine antisemitische Stimmung zu erzeugen bzw. diesbezügliche Ansätze zu aktivieren. An „Führers Geburtstag“ eröffnet das neugeschaffene Sprachrohr der Besatzungsmacht, „Neues Europa“, eine entsprechende Kampagne. ${ }^{13}$ Im Mai 1941 wird der Oberrabbiner Z'wi Koretz wegen angeblicher achsenfeindlicher Umtriebe verhaftet und nach Wien abtransportiert - dorthin, wo er zwei Jahrzehnte zuvor promoviert hatte: makabererweise ausgerechnet über Höllenschilderungen. ${ }^{14}$ An seiner Stelle bestimmt der deutsche Feldkommandant den mediokren Saby Saltiel zum „Prā-

11 Zum ganzen Komplex der Geschicke Griechenlands während der Okkupationszeit s. Hagen Fleischer, Im Kreuzschatten der Mächte: Griechenland 1941-1944. 2 Bände, Frankfurt a.M. 1986 - Zur Quellen- und Literatursituation auch H. Fleischer, Greece under the Axis Occupation. A Bibliographical Survey, in: latrides, Greece in the 1940s, Bd. II (A Bibliographical Companion), S. 1-79; eine stark erweiterte griechische Version, ebenfalls annotiert, in: I Ellada sti dekaetia 1940-1950, Athen 1984, Bd. II, S. 13-181.

12 L.S. Stavrianos, The Jews of Greece, in: J. Central European Affairs 8 (1948), S. 260; ebenso: Molho, In Memoriam I, S. 42.

13 Nea Evropi, 20.4.1941. - Vgl. die Klage des ${ }_{n}$ Sonderkommando Rosenberg ${ }^{\star}$, Für den Durchschnittsgriechen gibt es bisher kaum eine Judenfrage. Er sieht nicht die politische Gefahr des Weltjudentums und glaubte sich wegen der verhältnismäßig geringen zahlenmāßigen Stärke vor einer kulturellen und wirtschaftlichen Bevormundung durch die Juden sicher. (BA, NS 30/75)

14 Hirsch S. Koretz, Die Schilderung der Hölle im Koran und ihre Vorbilder in der jüdischen Literatur, Wien 1925 (masch.-schr. Diss.) 
sidenten“. Gleichzeitig wird eine vom Metaxas-Regime aufgelōste faschistoide Organisation, die EEE, als potentielle antisemitische Hilfstruppe wieder zugelassen. ${ }^{15}$ Mitfederführend ist hier das „Sonderkommando Rosenberg (spāter „Einsatzstab Reichsleiter Rosenberg“), das mit „der großzügigen und verständnisvollen Unterstützung“ der Wehrmachtsdienststellen jahrhundertealte jüdische Kunstschātze und Bücher ${ }_{n}$ sicherstellt", tausende von Banksafes auf der Suche nach ngeheimem Aktenmaterial ... planmäßig überprüft", allein in Saloniki in Zusammenarbeit mit der Geheimen Feldpolizei über 50 Hausdurchsuchungen mit anschließendem Verhör vornimmt und zugleich - was gefāhrlicher ist, aber kaum auffällt - versucht, die statistischen Voraussetzungen für künftige Aktivitäten zu schaffen. ${ }^{16}$ Die ohnehin bereits überhöhte Schätzung von 78500 erscheint dem kooptierten Frankfurter „Experten für Hebraica“, J. Pohl, jedoch noch zu niedrig, da er bewußte Tāuschungsmanöver der Betroffenen argwöhnt; im Herbst 1941 sucht er daraufhin "die meisten Judengemeinden “ persönlich auf, doch seine auf eine Kopfzahl von 100000 zielenden Vermutungen sind nicht nur in der Endsumme, sondern zumeist auch im Detail zu hoch gegriffen. ${ }^{17}$

Tatsāchlich liegen den Kopfjägern nur die Ergebnisse der nicht sonderlich zuverlāssigen Volkszählung von 1928 vor, die zudem - abgesehen von der allgemein beträchtlichen Unsicherheitsmarge - einen damals noch erheblich höheren jüdischen Bevölkerungsanteil aufweisen. Der weit genauere Zensus vom Oktober 1940, wenige Tage vor dem italienischen Überfall durchgeführt, kann hingegen erst lange nach Kriegsende systematisch ausgewertet werden. ${ }^{18} \mathrm{Da}$ auch die Unterlagen der Kultusgemeinden lückenhaft sind (bzw. in zwölfter Stunde gemacht werden), erweist es sich nicht allein für die Agenten des RSHA als unmöglich, eine annähernd sichere Zahl der „Rasse-“ oder auch nur der „Glaubens-Juden“ zu ermitteln. Auch die nach der Befreiung kursierenden Verluststatistiken ermangeln bis auf den heutigen Tag der verläßlichen Ausgangsbasis. Die am häufigsten genannten Zahlen, meist mit der unspezifizierten Datierung nvor dem Holocaust", sind 73000,75477 und vor allem $77377^{19}$, wāhrend einige Schātzungen noch wesentlich hōher ansetzen. ${ }^{20}$ Dabei bleibt es oft unklar, ob die Juden des bis 1946 italienischen Dodekanes ebenfalls berücksichtigt sind. Der Zensus von 1940 zählt jedoch lediglich 67591 Bürger (oder auch Ausländer) mosaischen Glaubens innerhalb der damaligen Grenzen ${ }^{21}$; hinzu müssen noch etwa

15 Molho, In Memoriam I, S. 33; vgl. Anm. 6.

16 BA, NS 30/75; vgl. auch: Molho, In Memoriam I, S. 37.

17 Ebenda; J. Pohl, Die Zahl der Juden in Griechenland, in: Weltkampl 3 (1942), S. 221 f. - Die überhöhten Ziffem gehen jeweils auf stark übertriebene Schätzungen der Thessalonicher Juden zurück, die den Bevōlkerungsschwund der letzten Jahrzehnte offensichtlich nicht berücksichtigen. Vgl. auch Anm. 23.

18 Die in Leichtmetallkisten verschlossenen Unterlagen gehen während der Kriegswirten vertoren, werden dann noch während der Okkupationszeit 2.T. aus dem Meer gefischt. Erste Ergebnisse werden 1946, eine ausführliche Darstellung wird 1950 publiziert. Doch die statistischen Daten zur Bestimmung der religiösen und sprachlichen Minderheiten werden erst 1961 veröffentlicht - in Gegenüberstellung zu den Resultaten der Volkszählung von 1951: Royaume de Grèce, Office National de Statistique, Résultats du Recensement de la Population effectuć le 7 Avril 1951, I, Athen 1961 (zit. Recensement).

19 Akropolis, 22.5.1945; PRO, F.O. 377/43775: R 12193; Stavrianos, Jews of Greece, S. 171; Matarasso, $\mathrm{Ki}$ 'omos, S. 9 und 56; u.v.2. bis hin zu Kathimerini, 29./30.4.1984 sowie anderen griechischen Zeitungen an diesem Tag anläßlich der Gedenkfeier des Jüd. Zentralrats. - Am besten ist noch die Schātzung von Reitlinger (Endlösung, S. 566), die allerdings auf einem fiktiven Zensus beruht.

20 Z.B. PRO, F.O. 371/43690: R 11387; W. Byford-Jones, The Greek Trilogy, London 1945, S. 67

21 Recensement, S. CXVII; bemerkenswert nahe kommt die Schātzung von 69600 im „Wannsee-Protokoll“, das allerdings ebenfalls die Dodekanesier und evtl. auch die thrazischen Juden in „Neubulgarien“ ausklammerr. Jedoch ist diese Ziffer nur eine von mehreren, die unter den Strategen der "Endlösung ${ }^{\mu}$ kursieren. 
2000 Dodekanesier gerechnet werden. ${ }^{22}$ Unter Einkalkulierung einer Dunkelziffer kann man also für den Raum des heutigen Griechenland etwas über 70000 Glaubensjuden annehmen. 23

Dank des optimal spāten Datums sowie der relativ strengen Erfassungsmodalitāten dieser Volkszāhlung verfügen wir über eine zuverlāssige Ausgangszahl wie in kaum einem anderen betroffenen Land, zumal offensichtlich auch ein Großteil der aus dem nationalsozialistischen Machtbereich geflüchteten nichtgriechischen Glaubensjuden miterfaßt ist. So verzeichnet der Zensus insgesamt 536 „Israeliten ${ }^{\text {" mit deutscher }}$ Muttersprache, von denen immerhin 434 diese noch täglich sprechen. ${ }^{24}$ Unter diesen sind neben einer Minderheit Alteingesessener ${ }^{25}$ zweifellos viele jener Neu-Immigranten zu suchen, die Griechenland nicht nur als Durchgangsstation nach anderen Làndern ansahen und die nun infolge ihrer Sprachkenntnisse als potentielle Spione für besonders gefährlich galten. ${ }^{26}$ Hingegen benutzten alle 35 Juden mit Jiddisch als Muttersprache im täglichen Gebrauch bereits Griechisch und deuten somit auf ansässige, idiomatisch meist schon wāhrend einer Generation assimilierte Aschkenasim-Splitter. Ebenfalls lānger ansāssig - wenn auch meist weiterhin als auslāndische Staatsbürger ist das Gros der Glaubensgenossen, die zur Mutter- (bzw. Umgangs-) Sprache folgende

22 Nehama, Israilitiki Koinotis, S. 250. - Um einen Vergleich mit dem inzwischen vergrößerten Griechenland zu ermöglichen, interpoliert die Nachkriegsstatistik für den Dodekanes von 1940 die Zahlen eines lokalen Zensus von 1947; dieses Verfahren gewährleistet unter dem Strich annāhernd richtige Analogien - mit der (unberücksichtigten? Ausnahme der jüdischen Bevölkenungsgruppe, die 1947 eben noch 70 Köpfe zählt. (Recensement, S. CXV bzw. CXVIII).

23 Die am häufigsten ritierte Angabe (77 377) basiert auf einem längst überholten jüdischen Bevōlkenungsanteil in Saloniki von 55000-56000. Indessen raumen selbst jüdische Quellen ein, daß diese einst beherr schende Gruppe 1940/41 bereits deutlich unter 50000 abgesunken ist (z.B. Hal Lehman, Greece: Unused Cakes of Soap, in: Commentary, Mai 1946, S. 48). Das ist aber gleichbedeutend mit einem Absinken der Gesamtzahl auf die hier vermuteten $70000-72000$.

24 Recensement, S. CXVI, CXVIII; vgl. u.. Intervicw mit Hella Cougno-Löwi aus Karisbad, deren Eltem unmittelbar vor der deutschen Besetzung der ${ }_{n}$ Resttschechei“ nach Salonikj nachgekommen waren. Als allerdings der BBC 1942 zunehmend (noch untertriebene) Meldungen über das Schicksal der Juden in den Konzentrationslagem brachte, tat das der „k.u.k.-treue "Vater Löwi als „alliierte Greuelpropaganda“ ab.

25 Man kann als gesichert annehmen, daß diese Gruppe ortsansässiger germanophoner Juden ihre Kinder nahezu geschlossen auf die deutschen Schulen schickte - jedenfalls vor 1933, als das Verhältnis zu den deutschen (und österreichischen) Konsulatsbehörden sowie der Schulleitung noch mehr oder weniger gut war. Insbesondere gilt das für die Zeit bis zum Ersten Weltkrieg, als die jüdischen Gemeinden außenpolitisch überwiegend zur Doppelmonarchie (und dem Deutschen Reich) bzw. - anders formuliert - gegen das pogromgeschüttelte Rußland ausgerichtet waren. Während jedoch an der Athener Schule kein nennenswerter Anteil festzustellen war, bildeten die "Israeliten" an der Deutschen Schule im damals noch türkischen Salonikj tatsächlich mit Abstand die größte Glaubensgemeinschaft - so etwa im Schuljahr 1910/11 123 von insgesamt 268 eingeschriebenen Schülem. Hiervon benutzte allerdings die große Mehrzahl (106) „Spaniolisch“ als erste Sprache - wiederum die größte Gruppe vor den lediglich 67 Kindern mit Deutsch als Muttersprache, die sich offensichtlich aber fast nur aus Protestanten und Katholiken zusammensetzten. Da andererseits unter den 17 aschkenasischen oder romaniotischen Juden auch Angehörige anderer Nationen vertreten waren, hatten - trotz anzunehmender psychologischer oder praktischer Vorteile - höchstens ein Dutzend jüdischer Schüler Deutsch als Muttersprache angegeben. (Jahresbericht der Deutschen Schule und der Kaufmännischen Fortbildungsschule in Saloniki, erstattet vom Direktor August Sigmund, Saloniki 1911, S. 35.)

26 "Vorwiegend deutschsprachige Juden, die aus Deutschland nach Griechenland eingewandert sind, haben sich zudem mangels Kennzeichnung und außerer Erkennbarkeit teilweise an deutsche Wehrmachtsangehōrige und Dienststellen heranmachen können, so daß sich ihnen genügend Möglichkeiten der nachrichtendienstlichen Betätigung für die Feindmächte bieten. Auch sonst gelingt es ihrien, auf diese Art und Weise allerhand Vorteile für sich zu erreichen. Die Internierung dieser besonders gefährlichen Juden erscheint daher als dringend notwendig." (Reichssicherheitshauptamt IV B 4b- 247/42 (1148), 11.7.1942 an Rademacher, $\mathcal{A}$, abgedruckt in: Daniel Carpi, Nuovi Documenti per la Storia dell'Olocausto in Grecia L'Attegiamento degli Italiani (1941-1943), in: Michael VII (1981), Tel Aviv, S. 173. 
Angaben machen: Französisch: 491 (114) / Italienisch: 157 (24) / Türkisch: 145 (35) / Russisch: 54 (18) / Englisch: 26 (6) / Rumānisch: 25 (2) / Jugoslawisch: 19 (9) / Armenisch: 16 (14) / Albanisch: 5 (1). ${ }^{27}$ Andererseits gehört ein wohl nicht unerheblicher Teil der 406 Glaubensjuden, die „sonstige ${ }^{4}$ Idiome nicht nur als Mutter-, sondern auch als Umgangs-Sprache angeben ${ }^{28}$, zu den Flüchtlingen vor dem langen Schatten der Nümberger Gesetze.

Wesentlich schwieriger noch ist es, die Differenz zwischen Glaubens- und „Rassejuden“ gemāß der Definition eben jener Gesetze zu eruieren, da der griechische Zensus nur sprachliche und religiöse Kriterien beachtet. Dennoch gibt es einige Anhaltspunkte. So bekennen sich lediglich 52731 der 53125 Erfaßten, die „spanisch bzw. judenspanisch" sprechen, zur mosaischen Religion. Von der Differenz sind wohl die meisten der 327 Orthodoxen konvertierte Sephardim, wohingegen es sich bei den Katholiken größtenteils um spanische bzw. lateinamerikanische Botschaftsangehörige oder andere ${ }_{n}$ arische ${ }^{\alpha}$ Spanier handelt. Ebenso dürften sich unter den verschiedenen Bekenntnissen anhāngenden nicht-mosaischen Deutschsprachigen (namentlich Protestanten und Katholiken) ${ }^{29}$ eine Anzahl getaufter Aschkenasim verbergen.

Zahlreicher sind zweifelsohne die zur Orthodoxie konvertierten graecophonen Juden, doch können diese mit keinem der gegebenen Parameter erfaßt werden. Die „kompetenten “ deutschen Dienststellen verzichten daher relativ früh auf systematische Aktionen gegen den genannten Personenkreis, zumal die unter solchen Umstānden allein möglichen sporadischen „Jagderfolge“ infolge der engeren sozialen Verflechtung mit dem Wirtsvolk die negativen politischen Konsequenzen auch nicht annähernd aufwiegen würden. (Häufigster Grund zum Glaubenswechsel war ohnehin dic „Mischehe“; mit „arischen “ Partnern Verheiratete wurden aber ausdrücklich von der Deportation ausgenommen, selbst wenn es sich um Glaubensjuden handelte. ${ }^{30}$ ) In der Praxis werden also zumindest die vor 1940 konvertierten Juden trotz gegenteiliger Ankündigungen nur relativ selten behelligt ${ }^{31}$ - jedenfalls kaum stārker als ihre ebenfalls stets gefāhrdeten ,arischen“ Landsleute. ${ }^{32}$ Diese numerisch ohnehin nicht sonderlich ins Gewicht fallende Gruppe kann somit im weiteren Verlauf dieser Untersuchung vorerst vernachlāssigt werden.

Wie bereits erwähnt, beginnen die massiven antijüdischen Maßnahmen später als in den meisten anderen Ländern unter deutscher Kontrolle. Und das, obwohl Himmler

27 Recensement, S. CXVt, CXIII. Eine leichte Verfälschung in diesen Zahlen ist derauf zurückzuführen, daß die jeweils erste Zahl - mit dem Kriterium der Muttersprache - die 70 (im lokelen Zensus von 1947 erfaßten) dodekanesischen Juden einschließt Da von den sephardischen Gemeinden auf Rhodos und Kos tast nur die türkischen sowie die (allerdings meist evakuierten) italienischen Stantsbürger überlebten, erscheint bei diesen beiden Guppen die Differenz zur rweiten („reinen") Zahl von 1940 besonders hoch.

28 Ebenda Hierunter fallen etwa Flüchtlinge aus Polen und der CSSR, aber auch aus Lindern, die noch nicht unmittelbar bedroht sind. In der gleichen Kategorie wird allerdings auch ausländisches Personal erfaße.

29 Recensement, S. CXVf.

30 Eine Minderzahl Vorkriegskonvertiten sowie Ehepartner von Christen wurden - 2.T. auch aus anderen Gründen - ins KZ Chaidari gespert, jedoch am 7.10.1944 gemeinsam mit den ebentalls geschützten“ 19 argentinischen Juden wieder freigelassen. (Antonis I. Phlountzis, Chaidari, 2. erw. Ausg., Athen 1986, S. 382.)

31 Offiziell befreit jedoch „der Austritt aus dem jüdischen Glaubensbekenntnis nicht von der Kennzeichnung“" (Molho, In Memoriam I, S. 136). Auf der anderen Seite stellen sich eine Anzahl Konvertiten sogar als "Experten" dem SD zur Verfügung (Evraiki Estia, 4.7.1947)

32 Zum hohen Blutzoll der griechischen Zivilbevölkerung durch „Sühnemaßnahmen“ u^.: Hagen Fleischer, Antipoina ton germanikon dynameon katochis stin Ellada 1941-1944, in: Mnimon 7 (1979), S. 182-195. 
bereits am 2. Oktober $1941 \mathrm{im}$ Anschluß an eine aktuelle Lagebesprechung in der Wolfsschanze das Saloniki-Problem anschneidet: Die dortige große jüdische Kolonie

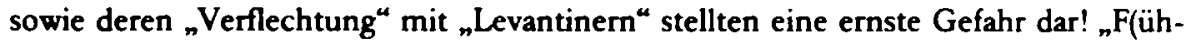
rer) pflichtet ihm bei und verlangt, jüdische Elemente aus S(aloniki) zu entfernen. " 33 Da jedoch die lokalen Militärbehörden feststellen, daß - im Gegensatz zur offiziellen Sprachregelung - die jüdische Beteiligung am erwachenden griechischen Widerstand eher unterproportional ${ }^{34}$ und zudem ein koordiniertes Vorgehen mit den beiden anderen Besatzungsmāchten noch nicht abzusehen ist, begnügt man sich vorerst, die unerwünschte Minderheit durch die Hungersnot des ersten Okkupationswinters dezimieren zu lassen. 35

Den ersten organisierten Schlag gegen die Juden in Saloniki lōst paradoxerweise die (kollaborierende) griechische Generalinspektion für Mazedonien aus, die sich bei der Militärverwaltung beklagt, daß jene - im Gegensatz zur griechischen Bevölkerungsmehrheit - nicht zu Arbeits- oder Sachleistungen herangezogen würden. ${ }^{6}$ Daraufhin befiehlt der „Befehlshaber Saloniki-Ägäis“ die öffentliche Registrierung der arbeitsfāhigen männlichen Juden (bis 45 Jahre). Am 11. Juli 1942 finden sich 8000-9000 Angehörige der betroffenen Jahrgänge - sinnigerweise - auf dem „Freiheitsplatz“ ein, wo sie unter entwürdigenden Schikanen gemustert werden. ${ }^{37} \mathrm{Da}$ die meisten ein Arbeitsverhāltnis nachweisen können, fallen nur knapp 3500 Mānner unter die neu eingeführte Arbeitspflicht. ${ }^{38}$ Von ihnen werden etwa $\mathbf{3 0 0 0}$ beim Straßen- und Flugplatzbau eingesetzt, 34 der kräftigsten im Chrombergwerk, und annāhernd 500 Facharbeiter werden für diverse Spezialaufgaben zwangsverpflichtet. Vor allem die „Straßenbaujuden“ kommen mit der ungewohnten Tätigkeit - bei völlig unzureichender Verpflegung und Unterbringung - nicht zurecht. „Zu schweren körperlichen Arbeiten taugten sie nicht viel ${ }^{\text {, }}$, resumiert der "Wehrwirtschaftsoffizier Saloniki“ spōttisch, so „holte sich ein hōherer Prozentsatz Lungenentzündung und starb. Daraufhin wurde vom Befehlshaber die Zwangsarbeitspflicht am 17. Oktober 1942 aufgehoben. "39

Unerwāhnt läßt der Wehrwirtschaftsoffizier dabei allerdings, daß an diesem Tag mehrwöchige Verhandlungen zwischen der Militärverwaltung (Dr. Merten) und der Kultusgemeinde in einer Vereinbarung enden, mit der letztere ihre bedrāngten Glau-

33 G. Engel, Heeresadjutant bei Hitler 1938-1943, hrsg. v. Hildegard v. Kotze, Stuttgart 1974, S. 111; ebenso in: Staatsanwaltschaft Bremen, $29 \mathrm{Js} 1 / 70, \mathrm{Bd}$. I, Bl. $76 \mathrm{f}$.

34 In der Tat hatte die jüdische Kolonie in Saloniki entscheidenden Anteil an der Entwicklung der griechischen Linken. Dennoch ist selbst dort die große Mehrheit eindeutig konservativ, was die defaitistischJoyaje" Haltung während der Okkupation erklärt. Unter diesem Blickwinkel wird es auch verständlich, wenn nach dem Krieg die einschlägige jüdische Literatur positive Bezugspunkte zu schaffen sucht, indem sie dem eigenen Widerstand einen weit überhōhten Stellenwert einräumt. Namentlich Kabeli, Resistance of Greek Jews, operiert dabei z.T. mit fiktiven Heldentaten und Zahlen.

35 Im schwarzen Winter 1941/42 sterben v.a. im Großraum Athen-Piräus etwa 100000 Griechen an Hunger - obwohl z.T. wesentlich höhere Schätzungen kursieren (vgl. Fleischer, Kreuzschatten, S. 117 f.). Der Anteil der jüdischen Opfer lag wohl unter $1 \%$.

36 St-A Berlin: 3P(K) Js 10/60, Bd. IV, Bl. 191: Chef SiPo/SD IV B4b 2427/42 geh. (1148), 18.8.1942; u.va

37 St-A Bremen: 29 Js 1/70, Bd. IV, Bl. 578 ff.: Eichmannprozeß, 47. Sitzung. - Der Befehl hierzu erging am 7.7.1942 und wurde am 9.7. in Nea Evropi publiziert.

38 Bundesarchiv-Militärarchiv Freiburg (MA) Wi IC 1.17: Wehrwirschaftsoffizier Salonikj 6002/42, 30.10.1942. - Insgesamt wurde zwar eine höhere Zahl an Gemusterten über die Presse aufgerufen (Nea Evropi, 25.7, 2./15./26.8, 2./4./8./11./16./20./25.9.1943), doch insbesondere die letzteren kamen nicht mehr zum Einsatz.

$39 \mathrm{MA}$, Wi IC 1.17: WO Saloniki, 6002/42, 30.10.1942; ebenda, WO Saloniki 6058/42, 14.11.1942; s. auch: Molho, In Memoriam I, S. $42 \mathrm{ft}$. 
bensbrüder freikauft. Die Auslöse beträgt nach langem Verhandeln in inflationären Drachmen einen Milliardenbetrag, umgerechnet etwa 10000 Goldsovereigns; darüber hinaus muß der historische jüdische Friedhof, auf dem in 450 Jahren Hunderttausende Sephardim ihre letzte Ruhestātte gefunden haben, den griechischen Kommunalbehōrden zur Nutzung überschrieben werden. ${ }^{40}$

Der deutscherseits genannte ${ }_{n}$ höhere Prozentsatz ${ }^{\star}$ der Todesopfer betrug nach jüdischen Schātzungen $12 \% 41$, also etwa 400 . Von den Úberlebenden flüchten einige wenige zu den thessalischen Partisanen, während der Großteil der Heimkehrer sich in beklagenswertem Zustand befindet. Immerhin wird ihnen eine mehrwöchige Galgenfrist zur Erholung eingerāumt, wobei das Lösegeld wohl eine geringere Rolle spielt als der italienische Einflußs.

In der Tat können die Italiener mit ihrer geschickten Hinhaltestrategie - im Rahmen des ansonsten für sie wenig schmeichelhaften „Kondominiums ${ }^{\text {" }}$ - gerade in der Judenfrage den vermutlich wichtigsten Pluspunkt ihrer Besatzungsgeschichte verbuchen. Konsequent weisen sie alle Berliner Pressionen zurück, parallel mit den einzuleitenden deutschen Maßnahmen in der eigenen Zone die gleichen Restriktionen, als ersten Schritt aber zumindest die Kennzeichnung der Juden einzuführen. Obwohl man sich im Reichssicherheitshauptamt über diese Ablehnung sowie die "unhaltbare" italienische Begründung echauffiert ${ }^{42}$, bleibt keine Alternative, als das Veto schließlich doch zāhneknirschend zu akzeptieren.

Unter Hinweis auf eben diese Haltung des Achsenpartners gelingt es jedoch dem Gesandten („Bevollmāchtigten des Reichs") Altenburg, auch für den deutschen Machtbereich einen Aufschub der geplanten Deportationen zu erreichen. Geschickt argumentiert er bei seiner Ablehnung, daß eine ${ }_{n}$ Sonderregelung ${ }^{*}$ allein für die deutsche Zone wenig Sinn habe, da auch dort ${ }_{n}$ die wirtschaftlich mächtigen Juden ${ }^{4}$ die italienische Staatsangehōrigkeit und somit einen Freipaß besäßen. 43

Altenburgs Hoffnung, mit dieser Koppelung an den eigenwilligen italienischen Verbündeten das gesamte Projekt zum Scheitern zu bringen, erfüllt sich aber nur für wenige Monate. Ende 1942 verliert man nämlich in Berlin die Geduld. Im Dezember wird die Registrierung der im Juli nicht erfaßten Juden von Saloniki nachgeholt ${ }^{44}$, und

40 In anderen deutschen Akten wird das Ablösegeschäft allerdings erwähnt, 2.B.: BA, R 7 VIIl/14: GMS 22106, 4.2.1943; R 7 VIII/103: II Bg3, Besprechungsvermerk 31.10.1942. Vgl. darüber hinaus: St-A Berlin 3P(K) Js 10/60, passim: Die deutschen, jüdischen und - anderen - griechischen Zeugenaussagen sind oft widersprüchlich, insbesondere auch in dem Punkt ob die bald darauf eingeebnete Nekropole enteignet oder jabgetreten" wurde ... (vgl. auch: Nea Evropi, 9.12.1942). Der Auslösebetrą von ebenfalls strittiger Hōhe wurde offiziell zur Bezahlung griechischer Arbeiter verwendet, die an Stelle der Juden traten; doch werden beträchtliche Summen offensichtlich in dunkle Kanäle abgezweigt, darunter mit ziemlicher Sicherheit auch in Mertens Tasche.

41 Roth, Last Days, S. 51; Molho, In Memoriam I, S. 47; vgl. auch: Matarasso, Ki'omos, S. 25 ff.

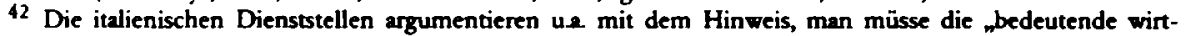
schaftliche Macht der italienischen Juden im Mittelmeerraum“ ins Kalkül ziehen! PAAA, Inland IIg, Bd. 190: RSHA IV B4b-2427/42 geh. (1148), 11.7.1942; u. $\overline{\mathrm{s}}$

43 ADAP, Serie E, Bd. III, Göttingen 1974, S. 232 f., vgl. S. 454. - Dr. Günther Altenburg, Karrierediplomat im Gegensatz zu den SA-Gesandten“ in den anderen Südoststaaten, war eine der positivsten Persōnlichkeiten der Okkupationsszene. Auch gegenüber Ribbentrop sowie militärischen Dienststellen trat er oft nachdrücklich für griechische Belange ein. Am 3.11.1943 verließ Altenburg schliefllich auf eigenen Wunsch Athen: primär, da er es leid war, die politische Verantwortung für - oft genug verantwortungslose Initiativen anderer zu tragen.

44 Nea Evropi, 20.11, 11.12.1942. 
wenige Tage spāter senden Himmler und Eichmann45 einige ihrer „bewährtesten“ Mitarbeiter nach Griechenland. Dort kündigt der Chef des Sonderkommandos, Hauptsturmbannführer Dieter $W$ isliceny, den führenden deutschen Dienststellen eine

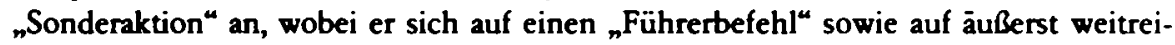
chende Vollmachten seitens des Reichssicherheitshauptamts und des Auswärtigen Amtes berufen kann: Die Juden im deutschen Machtbereich - ohnehin eine Fünfte Kolonne der Alliierten im Falle einer Invasion - seien unverzüglich ins Generalgouvernement abzutransportieren, um dort , in einem geschlossenen Siedlungsraum “ für die Kriegswirtschaft zu arbeiten. Verantwortlich für alle Judenangelegenheiten“ zeichne künftig das SD-Sonderkommando, vor Ort unterstützt von der Abteilung Militärverwaltung (Merten) beim Befehlshaber Saloniki-Ägäis. Hingegen habe sich die Gesandtschaft "völlig herauszuhalten “.46

Altenburg bleibt somit nur die unerfreuliche Aufgabe, seinen italienischen Kollegen Ghigi am 12. Januar 1943 von der bevorstehenden Aktion in Kenntnis zu setzen und ihm zugleich zu versichern, die Maßnahmen beträfen keine Juden italienischer oder neutraler Staatsangehōrigkeit. Ghigi hōrt „nicht ohne Bedauem “ zu, rāumt dann aber ein, ${ }_{n} \mathrm{da}$ wir in der deutschen Besatzungszone natürlich machen kōnnten, was wir wollten “. 47 Erst spāter wird sich zeigen, daß die Italiener selbst in diesem Punkt durchaus differenzierte Ansichten vertreten.

In Mazedonien hat mittlerweile der Countdown für Auschwitz begonnen. Nach verschiedenen vorbereitenden Maßnahmen informiert Merten am 6. Februar 1943 die Jüdische Kultusgemeinde, „kraft der dem Befehlshaber Saloniki-Ägäis verliehenen Rechtsetzungsbefugnis “ sei ab sofort folgendes angeordnet: ${ }_{n}$ Alle in Saloniki ansāssigen Juden - ausgenommen diejenigen ausländischen Staatsangehörigen, die sich durch einen gültigen $\mathrm{Paß}$ als solche ausweisen kōnnen“ - seien unverzüglich, als Juden zu kennzeichnen “ und müßten , in einen besonderen Stadtteil ${ }^{\star}$ umsiedeln. Die Durchführung wie auch die Präzisierung der angeordneten Maßnahmen werde der "Außenstelle Saloniki des SD übertragen ${ }^{48}$, die von Wisliceny und dessen Stellvertreter Alois Brunner geleitet wird.

Bereits am 12. Februar erläßt Wisliceny detaillierte Bestimmungen über das „Judenkennzeichen“ (Stern), das „von allen Juden vom vollendeten 5. Lebensjahr getragen werden ${ }^{\star}$ muß. Zugleich definiert er, wer ${ }_{n}$ als Jude im Sinne der oben angeführten Anordnung ... gilt“.49 Anderntags wird den Juden die Benutzung von Telefonen sowie öffentlichen Verkehrsmitteln verboten. Nach Einbruch der Dunkelheit ist ihnen das Betreten der Straßen untersagt, und insbesondere droht bei unerlaubtem Verlassen ih-

45 Auf einem Quellenirrtum beruht die Angabe von Reitlinger (Endlōsung, S. 421), Eichmann sei persönlich nach Griechenland gekommen. Merten greift später, in dem gegen ihn geführten Ermittungsverfahren, diesen Irtum begierig auf, um von eigener Verantwortung abzulenken. Gegen diese These spricht aber nicht nur die Inkongruenz seiner eigenen Aussagen, sondem auch das Fehlen jeglichen dokumentarischen Beweises sowie das gegensätzliche Zeugnis aller anderen Beteiligten, darunter auch Eichmanns selbst. (St-A Berlin 3P(K) Js 10/60, passim, v.2. Bd. VIII, Bl. $123 \mathrm{ff.;} \mathrm{Bd.} \mathrm{DX,} \mathrm{Bl.} 177 \mathrm{ff}$; Bd. XIV, Bl. $43 \mathrm{ff}$.)

46 St-A Berlin 3P(K) Js 10/60: Bd. V, BI. $193 \mathrm{ff}$; Bd. VI, Bl. 26ff.; Bd. VII, Bl. 42; Bd. XIV, BI. 14, 41, 85f;; Georg Vogel, Diplomat unter Hitler und Adenauer, Düsseldorf 1969. S. 94 ff.

$47 \mathrm{PAAA}$ Inland IIg/190: Altenburg 118/13.1.1943.

48 Nea Evropi, 6.2.1943; Bfh. Saloniki-Ägäis, Abc Militärverwaltung (MV)-Dr. Me 1237/6.2.1943, in: Molho, In Memoriam I, S. 135.

49 Nea Evropi, 12.2.1943; Außenstelle der SiPo und des SD in Saloniki, IV B4, 12.2.1943, in: Molho, In Memoriam I, S. $136 \mathrm{f}$. 
res stāndigen Wohnsitzes sofortige Erschießung. Zugleich wird dem Anfang 1942 nach Saloniki zurückgekehrten Oberrabbiner Koretz „befohlen, nicht nur die Juden in Saloniki und näherer Umgebung, sondern alle Juden im gesamten Bereich des Befehlshabers Saloniki-Ägäis zu betreuen “, da "die gesamten Judenfragen im Befehlsbereich einheitlich gelöst werden müssen". 50

Aus der Sicht des SD erweist es sich bald als guter Schachzug, die nunmehrige Doppelfunktion des ohnehin überforderten Koretz - seit Ende 1942 auch Präsident der Kultusgemeinde - auf die anderen mazedonischen Gemeinden auszudehnen. Denn jener, stolz auf seine nostalgisch verbrämten Wiener und Berliner Erfahrungen aus den Zwanzigerjahren, kann sich offensichtlich auch nach seiner zwischenzeitlichen Verhaftung nicht vorstellen, daß in Auschwitz eine Hōlle wartet, gegenüber der die von ihm ehemals analysierten traditionellen Schilderungen zu Ammenmärchen verblassen. ${ }^{51}$ Infolgedessen drängt Koretz die Mitglieder seiner Gemeinde - und in-

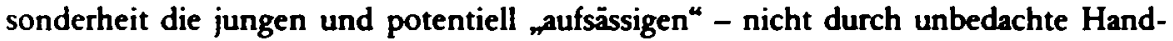
lungen deutschen Unwillen zu erregen und die Fahrt in das verheißene neue Siedlungsgebiet in der Krakauer Gegend zu gefährden. 52 Abschreckend wirkt zudem die Geiselnahme für Wohlverhalten sowie die öffentliche Hinrichtung gefaßter Flüchtlinge ${ }^{53}$, so daß nur ein geringer Prozentsatz der Betroffenen untertaucht und bei christlichen Landsleuten, bei den Partisanen oder in der italienischen Zone Asyl sucht. Das Gros der Gemeinde befolgt hingegen fatalistisch jede neue Verordnung.

Am 17. Februar ergehen weitere Bestimmungen über die Kennzeichnung jüdischer Wohnungen, Büros, Geschāfte und Grundstücke. $\$ 4$ Am 25. Februar wird den Juden mit sofortiger Wirkung die Mitgliedschaft in allen Organisationen, Körperschaften etc. untersagt. 55 Zur gleichen Zeit konstituiert das SD-Kommando einen nur ihm verantwortlichen $\sqrt{ }$ üdischen Ordnungsdienst ${ }^{\star}$ aus etwa 250 Hilfswilligen. Diese Milizionāre überwachen mit bemerkenswerter Brutalitāt die forcierte Umsiedlung in die neugeschaffenen Ghettobezirke, von denen das „Baron-Hirsch-Viertel“ - einst als provisorisches Asyl für die Flüchtlinge der russischen Pogrome von 1903 errichtet - „praktischerweise ${ }^{\text {a }}$ an das Güterbahnhofsgelānde grenzt und daher in ein Durchgangslager umgewandelt wird. Mit erheblichem Aufwand wird das Viertel in den ersten Märztagen eingefriedet und durch strenge Bewachung von der Außenwelt abgeschnitten. 56

Mittlerweile, am 1. Mārz, werden alle Juden aufgefordert, $n^{z u}$ statistischen Zwekken " eine detaillierte Erklārung über ihr Hab und Gut abzugeben. Am 8. März wird bei der griechischen Administration eine „Dienststelle zur Verwaltung des Judenver-

50 Bfh. Saloniki-Ägäis, Abt. MV-Dr. Me, 1517/13.2.1943, in: Molho, In Memorian I, S. 138 f.

$51 \mathrm{Vgl}$. Anm. 14. - Das in der Literatur vorherrschende, primär aul Molho zurückgehende, Verdammungsurteil über Koretz vergrōbert zu stark, als daß es dem Rabbi gerecht werden kōnnte. Denn trotz seiner Schwäche, EntschluMosigkeit und illusionären Naivität - gepaart allerdings mit persōnlichen Ambitionen - handelte er wohl doch bona fide. Die meisten unmittelbar Betroffenen bezweifeln allerdings auch das; ein Uberlebender aus Auschwitz war bereit, die mildere Interpretation gelten zu lassen, kommentierte jedoch, auch der Weg zur Hölle sei mit guten Vorsätzen gepflastert.. Estrongo Nachama, Interview mit Vf. (1976). Vgl. auch: Nathan Eck, New Light on the Charges Against the Last Chief Rabbi of Salonica, in: Yad Vashem Bulletin 17 (Dez. 1965), S. 9-15.

52 St-A Berlin 3P(K) Js 10/60, Bd. III, Bl. 22 ff.; Matarasso, Ki'omos, S. $37 \mathrm{ff}$.

53 Matarasso, Ki'omos, S. 41; Eck, New Light, S. 14; Roth, Last Days, S. 52; Interview E. Nachama; Phlountzis, Chaidari, S. 378.

54 Außenstelle SiPo/SD Saloniki, IV B4, 17.2.1943, in: Molho, In Memoriam L, S. 140.

35 Bfh. Salonikj- $\ddot{A}_{g}$ äis, Abt. MV-Dr. Me, 2014/25.2.1943, in: Molho, In Memoriam I, S. 141.

56 Molho, In Memoriam I, S. $68 \mathrm{ff}$. 
mögens" (YDIP) eingerichtet, und in den folgenden Tagen werden in einem Crescendo von Verordnungen alle Vermögenswerte beschlagnahmt und demonstrativ dem griechischen Staat übertragen. 57

Die Nachrichten über die brutale Nacht- und Nebelaktion gegen die „Rassegefāhr-

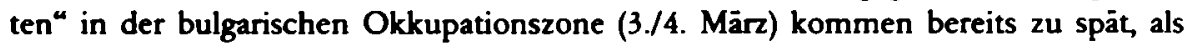
daß sie noch eine aufrüttelnde Wirkung für die entmündigte Judenschaft von Saloniki haben könnte. „Dies irae ${ }^{\text {us8 }}$ bricht für sie bereits am 15. März an: Vom letzten Geld, das den Eingeschlossenen verblieben ist, darf jedes Familienoberhaupt in einer konsequent durchgespielten Farce einen „Anrechtschein“ über 600 Zloty zur Auszahlung in der „neuen Heimat" eintauschen; Stunden spāter verlāßt bereits der erste Deportationszug die Stadt in Richtung Norden. Bestimmungsort ist jedoch nicht das verheiBene Brzesko (bei Krakau), sondern die Rampe von Auschwitz. Von den etwa 2400 Deportierten werden am 20. April nur 417 Mānner und 192 Frauen ins Lager eingeleitet, der große Rest geht sofort nach der Selektion ins Gas.59

Die Verantwortlichen der Vernichtungsmaschinerie lassen sich auch nicht stören, als Rabbiner Koretz - aufgeschreckt durch zunehmende Ausbrüche aufgestauter Empōrung in seiner Gerneinde - bald darauf den ${ }_{n}$ sichtlich peinlich berührten “ Kollaborationspremier Rallis bittet, sich für die jüdische Sache zu engagieren. 60 Für einen reibungslosen Ablauf der „Entjudung " benötigt man den Rabbiner nicht mehr, so wird er amtsenthoben und vorerst in einem Privathaus festgesetzt. In dichtem Rhythmus wird das Baron-Hirsch-Ghetto wieder gefüllt und geleert, im selben Rhythmus verlassen Transporte die mazedonische Metropole: weitere vier im Mārz, neun im April, zwei im ersten Maidrittel. Die angestrebte durchschnittliche "Abtransportquote ${ }^{\text {a }}$ von 2800 Personen pro Zug erfordert eine restlose Ausschōpfung der „Ladekapazitāt", so daß einige der in Viehwaggons Zusammengepferchten jeweils schon auf der Fahrt zugrunde gehen.

Auf diese Art verlassen bis zum 9. Mai 1943 über 42000 Juden die deutsche Zone, darunter mit den beiden letzten Transporten auch 2034 aus den kleineren Gemeinden Mazedoniens sowie aus dem Demotica-Streifen an der türkischen Grenze. ${ }^{61} \mathrm{Zu}$ Recht triumphiert das theoretische Organ der Hāscher am 1. Juni: „Die Zahl der heute noch in Griechenland lebenden Juden ist inzwischen stark zurückgegangen. "62 Am selben Tag folgen zudem 820 „Privilegierte ${ }^{\mu}$ - Intellektuelle, Mitglieder des Ältestenrates, Hilfspolizisten sowie andere Kollaborateure minderen Ranges - alles Juden, denen Wislicenys Stab bevorzugte Behandlung versprochen hatte. Doch statt in Theresienstadt landen auch sie in Auschwitz-Birkenau. Lediglich 308 erhalten eine Registrierungsnummer, während die anderen umgehend vergast werden - für Birkenau immerhin noch eine „günstige“ Relation. ${ }^{63}$ Der letzte Transport von Saloniki nach Ausch-

\footnotetext{
$\$ 7$ Matarasso, Ki'omos, S. $34 \mathrm{ff}$, S. $97 \mathrm{ff}$ - Vgl. auch den apologetischen Bericht des Leiters der Ypiresia Diacheiriseos Israilitikis Periousias (YDIP) I. Douros, in: Landgericht Berlin, Wiedergutmachungskammer, Bd. 292

58 Molho, In Memoriam I, S. 81.

39 Vgl. Tabelle 1.

60 Früher BA, unsignierter Bestand, vor. Magazin-Nr. 213d, jetzt in PAAA: Bevollmächtigter des Reiches für Griechenland, Bd. X: Briefe Wisliceny - Schönberg, 15./16.4.1943.

61 Molho, In Memoriam I, S. 106.

62 Die Judenfrage in Politik - Recht - Kultur und Wirtschaft, 1.6.1943.

63 Tabelle 1.
} 
witz erfolgt am 10. August. Opfer sind die 1800 Uberlebenden der mindestens 2000 unverheirateten Mānner, die Ende März - bereits nach Beginn der Deportationen - zu Streckenarbeiten nach Bōotien geschickt worden waren ${ }^{64}$, wo die meisten neuralgischen Punkte der einzigen und oft von Partisanen unterbrochenen Nord-Süd-Bahnverbindung lagen.

Eine Woche zuvor, am 2. August, war ein relativ kleiner Transport nach BergenBelsen abgegangen. Der Bestimmungsort verrāt, daß es sich diesmal um echte Privilegierte handelt, die sich daher auch nicht der Eintātowierung einer Nummer unterziehen müssen : 74 griechische Juden - darunter Koretz und seine Familie, andere Würdentrāger sowie Kollaborateure, die sich besonders um die SD-Mission verdient gemacht hatten 65; hinzu kommen 367 Juden spanischer Staatsbürgerschaft.

Zu Beginn ihrer Aktion hatten die deutschen Stellen jene Juden mit (meist vermöge "historischer" Titel ererbter oder erworbener) fremder Staatsbürgerschaft sorgfāltig von jeder Verfolgung ausgenommen. Vor Beginn der Deportationen wurden allein im Raum Saloniki 511 spanische, 281 italienische, 39 türkische, je 6 portugiesische und argentinische sowie 4 Schweizer Juden registriert; hinzu kamen je einer mit bulgarischen bzw. ungarischen Papieren, 7 Staatenlose sowie schließlich 8 Bürger diverser Feindstaaten. 66 Ihr weiteres Schicksal hing davon ab, inwieweit die ${ }_{n}$ Heimatregierungen " willens waren, sich zu exponieren. So durften die Juden mit italienischen, portugiesischen, argentinischen und skandinavischen Pāssen bald schon aufatmen, da man in den zuständigen Hauptstädten grünes Licht für die "Repatriierung ${ }^{\mu}$ gab. Die Spanne zwischen Leben und Tod war schon durch ein Minimum an offiziellem Engagement zu überbrücken; das zeigt sich namentlich im Fall der spanischen und türkischen Staatsangehörigen, die trotz der lauen Haltung von Madrid bzw. Ankara gerettet wurden, da zumindest deren lokale diplomatische Vertretungen wachsames Interesse an den Tag legten. Auf der anderen Seite willigten die meisten Satellitenregime (Sofia, Bukarest, Agram, Preßburg/Bratislava) mehr oder weniger spontan ein, „ihre“ Juden auf dem Gebiet des Deutschen Reiches sowie in allen deutsch okkupierten Territorien ,in die allgemeinen Maßnahmen einzubeziehen ${ }^{4}{ }^{67}$

Auf das Schicksal in der von Bulgarien besetzten, de facto aber annektierten "neuen (ägäischen) Provinz Belomorie (Ostmazedonien/Thrazien) geht ein anderer Beitrag dieses Bandes ausführlicher ein. In diesem Kontext sei lediglich daran erinnert, daß die Sofioter Regierung, die als „Bundesgenossin“ natürlich viel mehr Spielraum besaß als etwa das Athener Kollaborationsregime, zwar im „Kernland" eine bemerkenswert positive Haltung gegenüber den jüdischen Mitbürgern mit bulgarischem $\mathrm{Paß}$ ein-

64 Molho, In Memoriam I, S. 87 und 94. - Die meisten aus dieser Gruppe befinden sich in einem derart erbärmlichen Zustand, daß die Selektionsquote in Auschwitz besonders ungünstig ausfallt. Das Gros der Uberlebenden wird bald darauf zu Aufräumungsarbeiten ins zerstōrte Warschauer Ghetto gebracht, wo nur die Robustesten überieben werden.

65 Der Spitzenkollaborateur V. Hasson, rechte Hand Wislicenys, zieht es allerdings vor, mit seinen engsten Kumpanen und einem zusammengeraubten Schatz unterzutauchen und sich uber die albanische Grenze abzusetzen. Nach dem Kriege wird er jedoch gefalt und ist der einzige jüdische Kollaborateur, der hingerichtet wird (1948).

66 PAA, Inland IIg/190: Generalkonsul Saloniki (Schōnberg), 103-J/15.3.1943.

67 PAAA, Inland II A/B-64/3: Rademacher, DIII 288g, 4.3.1943; u.v 2 
nimmt ${ }^{68}$, diese aber expressis verbis sofort aufgibt, sobald sich jene außerhalb der eigenen Landesgrenzen, etwa im Reich oder in Griechenland befinden. 69 Nicht die geringsten Skrupel empfindet das Regime in Sofia jedoch in den sogenannten „neuen Provinzen“, da dort die jüdische Minderheit als zusätzliches Hindernis für die eigenen Bulgarisierungsplāne angesehen wird. Am 22. Februar 1943 unterzeichnet daher der bulgarische Kommissar für Judenangelegenheiten Aleksander Belev mit dem bereits aus Frankreich bekannten SS-Hauptsturmführer Theodor Dannecker ein Geheimab-

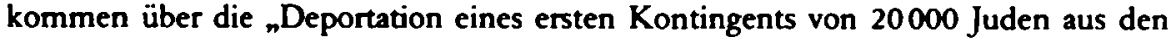
neuen bulgarischen Territorien in Thrazien und Mazedonien ".70

Bulgarische Effizienz offenbart sich, als nichts von der schnell, aber sorgfältig vorbereiteten Aktion durchsickert: tatsāchlich werden in der Nacht vom 3. zum 4. März die betroffenen Gemeinden Alexandroupolis, Komotini, Xanthi, Kavalla, Drama und Serres nahezu hundertprozentig ausgehoben, ihre verbliebenen ca. 4200 Angehörigen buchstäblich im Schlaf überrascht. ${ }^{71}$ Oft kaum mit dem Notdürftigsten bekleidet, werden sie bei Minustemperaturen zu provisorischen Sammelstellen (meist Tabakdepots) getrieben, dann mit "haarstrāubenden " Brutalitāten über die alte griechisch-bulgarische Grenze (Petrić) zum Donauhafen Lom gebracht, wobei manche Deportierte bereits an den Strapazen dieser ersten Transportphase zugrundegehen. In Lom werden (wohl am 20. März) 4209 Juden - worin etwa 150 aus dem jugoslawischen Pirot enthalten sind - in vier Fähren geladen; einige Uberzählige bringt man in kleineren Barken unter.

Seitdem wurde wiederholt die Ansicht geāußert, alle Gefangenen seien bereits vor oder spätestens während der Übergabe an die Deutschen in der Donau ertrānkt worden. ${ }^{2}$ Ein wahrer Kern dieser Gerüchte läßt sich nicht ausschließen. So gibt es mittlerweile Indizien, daß zumindest eins der alterssch wachen und überladenen Flußboote

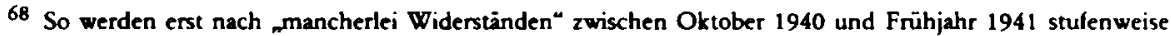
antijüdische Verordnungen und Gesetze nzum Schutze der Nation" erlassen, die jedoch deutscherseits öffentlich als "keine endgültige Lōsung" und noch susbaubedürftig“ bemängelt werden. Insbesondere zeigt man sich in Bedin befremdeh, als die bulgarische Zensur zeitweise sogar nazistische Machwerke wie den Film Jud Süßّ" verbietet (Völkischer Beobachter, 18.10.1940, 25.1.1941; Münchener Neueste Nachrichten, 19.3.1941; Die Judenfrage, 20.2.1941, 10.3.1941; u.va.) - Deutsche Pressionen bewirken dann zwar gradweise neue Restriktionen, die aber den SD bei weitem nicht zufriedenstellen. (Vgl. Hans-Joachim Hoppe, Bulgarien - Hitlers eigen williger Verbündeter, Stuttgart 1979, S. $138 \mathrm{ff}$.) Andere Autoren sehen die Sofioter Judenpolitik allerdings weit negativer. (V. Vicki Tamir, Bulgaria and Her Jews. The History of a Dubious Symbiosis, New York 1979).

69 S. Anm. 67; PAAA, Inland IIg/191: Deutsche Gesandtschaft Sofia 880/12.6.1943.

70 Tamir, Bulgaria and Her Jews, S. 292 f. - Da in den annektierten Gebieten nicht mehr als 10000-1 2000 Ju. den leben, muß die Differenz zwangsläufig mit "unerwünschten“ Elementen aus Altbulgarien aufgefültt werden - ein Faktum, dessen sich beide Signataren voll bewußt sind. (Vgl. Tamir, S. $190 \mathrm{ff}$.)

71 Molho (In Memoriam I, S. 104) nennt 4706 Verhaftete; diese Angabe muß wohl um einige Hundert verringert werden, da deutsche Quellen von 4210 brw. 4124 Deportierten sprechen. Die erste Ziffer stammt von Luther (3.4.1944), die zweite ist aus Dr. Korherrs Angabe für „Bulgarien“ zu errechnen. (Reitlinger, Endlōsung, S. 432 und 435; bzw. Jochen v. Lang, Das Eichmann-Protokoll, Gütersloh o.J., Anhang.)

1945 wird errechnet, daß die Vertustquote für die betroffenen Gemeinden rwischen $97 \%$ und $99 \%$ schwankt, womit sie - trotz einer geringen Dunkelziffer verschollener Flüchtlinge - in Griechenland eine traurige Spitzenposition innehaben (Matarasso, Ki'omos, S. 56). Bei den wenigen Uberlebenden handelt es sich fast durchweg um Personen, die bereits früher geflüchtet waren, um junge Leute, die zu $Z$ wangsarbeit nach Bulgarien verschleppt worden waren, was sich im Nachhinein als unfreiwillige Rettungstat erweist ( $T_{a}$ mir, Bulgaria and Her Jews, S. 193), oder aber um Juden mit fremder Staatsbürgerschaft. - Die von Hoppe in diesem Band genannte bulgarische Schätzung von 4057 Deportierten enthālt offensichtlich nicht die Todesfalle in den Sammellagem.

72 U. Molho, In Memoriam I, S. 105; Tamir, Bulgaria and Her Jews, S. 194 f. 
mit ihrer hilflosen Fracht unterging oder nerleichter $^{4}$ wurde ${ }^{73}$; nachweislich kam jedoch die Mehrzahl der Deportierten in Treblinka an, wo ihr mehrfach bezeugter überdurchschnittlich schlechter physischer Zustand eine analoge Selektionsquote zur Folge hatte. Von jenen, die diesen Massenmord und auch die nächsten Monate noch überlebten, wurden - einigen Zeugen zufolge - die meisten im Oktober zum Arbeitseinsatz ins zerstörte Warschauer Ghetto geschickt, wo sich ihre Spuren jedenfalls gānzlich verlieren. ${ }^{74}$

Gesichert scheint inzwischen lediglich zu sein, daß von den in Folge des Dannekker-Belev-Abkommens deportierten thrazischen Juden letzten Endes kein einziger mit dem Leben davon kam - ein Faktum, das noch unheimlicher wird, wenn die relativ „simple ${ }^{4}$ Erklärung, mittels eines schnellen und allumfassenden nassen Todes in der Donau, nicht mehr herangezogen werden kann.

Ein besseres Schicksal haben, wie bereits angedeutet, jene Juden, die Ansprüche auf den Schutz des neutralen Spaniens anmelden können. Der iberische Staat war bereits Ende des 19. Jahrhunderts mit gutem Beispiel vorangegangen, als er als erster einer Anzahl (sephardischer) Flüchtlinge vor den russischen Pogromen eine neue (alte) Heimstatt anbot. Daß hierbei auch historisch motivierte Schuldgefühle kompensiert werden, zeigt das bald darauf erlassene Gesetz, das Spaniolen die Möglichkeit gibt, sich um die spanische Staatsbürgerschaft zu bewerben. Was Saloniki betrifft, reagiert Madrid schnell auf die griechische Eroberung im Ersten Balkankrieg und die darauf folgende Aufhebung der Kapitulationen. Das spanische Konsulat wird angewiesen, für diesen bislang geschützten Personenkreis ein "Registro de Protegidos Españoles“ anzulegen. Dieses Privileg einer "Quasi-Staatsbürgerschaft" wird in den folgenden Jahrzehnten wiederholt $(1916,1924,1933)$ ausgebaut und untermauert. ${ }^{75}$ Dennoch machen nur wenige Sepharden hiervon Gebrauch - eine Unterlassung, die sich spāter rächen wird.

Als Anfang 1943 die Verfolgungswelle unübersehbar neue Dimensionen annimmt, machen die über 500 Privilegierten ihren Sonderstatus geltend. Doch bald zeigt sich, daß eine "Heimkehr ${ }^{\mu}$ ins unbekannte Land der Vorväter die einzige deutscherseits akzeptierte Alternative zur Deportation darstellt. Eine solche Entscheidung kann aber vom hilfsbereiten spanischen Geschäftsträger ohne vorheriges Placet seiner Regierung nicht getroffen werden. Da letztere stumm bleibt, drāngt Eberhard von Thadden, \udenreferent" in der Abteilung Inland II des Berliner Auswärtigen Amts, auf eine Präzisierung der spanischen Haltung. Wiederum versucht Madrid Zeit zu gewinnen,

73 Erikos Sevillias, Athens - Auschwitz, Athen 1983, S. XVII; Interview Nikos Stavroulakis, Kustos des Jüdischen Museums Athen, der Sevillias' Buch übersetzt und kommentiert herausgegeben hat.

74 Ebenda; Reitlinger, Endlösung, S. 432 und 435; Miriam Novitch, Le Passage des Barbares, Nice 1973, S. 77 und 86; vgl. auch Czech, Deportation, S. 21. Der dort erwihnte, am 26.3. (nicht 28.3.) in Treblinka eingetroffene Zug mit 46 Waggons kann keine „Umsiedler“ aus Saloniki, sondem nur solche aus der bulgarischen Zone enthalten haben. Es gingen keine Transporte aus der deutschen Zone nach Treblinka. (Vgl. auch Wisliceny in: Lang, Eichmann-Protokoll, S. 149). - Erwähnt werden soll, daß der Vf. die These vom Weitertransport der "Thrazier" von Treblinka nach Warschau nicht für gesichert hält. Da eine Anzahl Auschwitzer Juden (aus der deutschen Zone) den gleichzeitigen Arbeitseinsatz im ehemaligen Ghetto überlebte, erscheint es nicht stichhaltig, warum die angeblichen Gefāhrten aus Treblinka unter den gleichen Bedingungen bis auf den letzten Mann umgekommen sein sollen - und noch nicht einmal zuvor die Gelegenheit fanden, gegenüber ihren Landsleuten die obskuren Geschehnisse von Lom zu erhellen.

75 Haim Avni, Spanish Nationals in Greece and their Fate during the Holocaust, in: Yad Vashem Studies VIII (1970), S. 35 ff.; auch Reitlinger, Endlösung, S. 427. 
doch sind die Manöver - wenn etwa „unüberwindliche technische“ Transportprobleme vorgeschoben werden - allzu durchsichtig. ${ }^{76}$ Im Juli informiert daher schließlich Diaz, der Erste Sekretär der Botschaft in Berlin, den Judenreferenten, seine Regierung habe Verstāndnis für die deutscherseits angeführte ${ }_{n}$ sicherheitspolitische ${ }^{4}$ Notwendigkeit der Evakuierungen, sei aber selbst an einer Immigration der Sepharden nicht interessiert. Dennoch sehe man letztere ${ }_{n}$ im Prinzip als Spanier, wünsche also nicht, daß sie , in polnischen Lagern liquidiert" würden. Thadden zeigt sich empört, daß sein Gegenüber offensichtlich den Lügen der feindlichen Greuelpropaganda“ Glauben schenke, da ,von einer Liquidierung kcine Rede sein“ kōnne. Immerhin bietet er gleich darauf an, bis zu einer endgültigen Entscheidung Madrids könnten die sistierten Juden vorerst im Reich (an Stelle eines der gefürchteten Ostlager) intemiert werden. ${ }^{77}$

In der Tat werden die 366 mit dem wertvollen Dokument versehenen Sephardim sowie der spanische Vizekonsul Solomon Ezrati, der jüdischer Abstammung ist - dem erwähnten Privilegiertentransport angeschlossen, der am 2. August 1943 nach BergenBelsen abgeht. Von dort werden sie schließlich ein halbes Jahr spāter (4./7. Februar 1944) mit Hilfe der US-jüdischen Hilfsorganisation American Joint Distribution Committee gerettet und - via Barcelona - nach Palāstina evakuiert. ${ }^{78} \mathrm{Zu}$ betonen ist jedoch noch einmal ausdrücklich, daß lediglich 366 „Paß-Spanier“ aus Saloniki deportiert wurden, wohingegen wenige Monate zuvor der SD noch 511 (darunter offensichtlich vier bis fünf Doppelnennungen) registriert hatte. Die Differenz wurde - wie die deutschen Stellen indigniert vermerken - „illegal“ mit italienischen Urlauberzügen nach Athen ausgeschleust. ${ }^{79}$ Damit ist es an der Zeit, auf die Judenpolitik auch der dritten Okkupationsmacht näher einzugehen.

Beharrlich hatten sich die Italiener gegenüber den deutschen Beschwörungen der ,jüdischen Gefahr" nicht nur taub gestellt, sondern - wie auch im neubesetzten Frankreich - alle „Judenmaßnahmen " geradezu "sabotiert" ${ }^{\text {" }}{ }^{\circ 0}$ Auf Vorstellungen, die

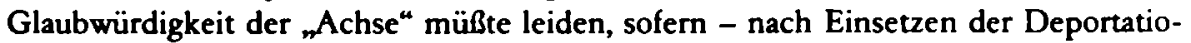
nen - nicht auch der italienische Partner in seiner weit größeren Besatzungszone nachzöge, erklärte sich Rom höchstens zu einer - zumindest partiellen - Internierung der Juden auf den Ionischen Inseln oder aber einer Evakuierung nach Italien selbst bereit. Eichmann verwarf diese Offerte als „ungenügend“ - zumal die einflußreichen Persönlichkeiten erfahrungsgemāß von solchen Maßnahmen ohnehin ausgenommen würden - und bestand stattdessen auf dem vorbehaltlosen Nachziehen des Achsen-

76 PAAA, Büro des Staatssekretärs, Griechenland Bd. IV: Altenburg 1660/12.6.1943; auch: AA Inland IIg/ 191, passim.

77 PAA, Inland IIg/191, passim, insbesondere: Thadden, Aufzeichnung zu Inland II, 2084g/21.7.1943.

78 Auch nach Ankunft der "Privilegierten" in Bergen-Belsen wurde die spanische Verzögerungstaktik fortgesetzt, insbesondere auch das Unvermögen betont, die Guppe im eigenen Land aulzunehmen. In der Diskussion zog man selbst den einheimischen Antisemitismus heran (Inland IIg/191, passim, u a : Deutsche Botschaft Madrid 5504/21.8.1943). Auf amerikanischen Druck erklärt sich Madrid schlie(lich bereit, mit geringstem eigenen Aufwand einen Lösungsvorschlag des "Joint" zu unterstützen und mit einem Transitvisum für die Eingeschlossenen die Voraussetzung für die Ausreise - über Barcelona und das UNRRADurchgangslager Fedhala bei Casablanca - nach Palastina zu schaffen. Istorikon Archeion Ethnikis Antistaseos 33-34 (1961), S. 28; Reitlinger, Endlōsung, S. 428; Novitch, Passage des Barbares, S. 31 f; Avni, Spanish Nationals in Greece, S. $54 \mathrm{ft}$.

79 PAA, Inland IIg/191: $3764 / 13.8 .1943$ - Inland II 2132g; Carpi, Nuovi Documenti, S. 158 f.

80 A (Bergmann), D III 246g/24.2.1943, abgedruckt in: Carpi, Nuovi Documenti, S. $177 \mathrm{f}$. 
partners. ${ }^{81}$ Dieser zog sich daraufhin auf seine Ausgangsposition zurück und bemühte sich mit bemerkenswerter Konsequenz darum, alle Vorstöße des SD in die eigene Zone abzublocken. ${ }^{82}$ Zugleich intensivierte man die eigenen Aktivitāten in den deutschen Enklaven, wobei die konsularischen Behörden ihre Schutzmachtrechte āußerst großzügig interpretierten. Selbst entfernte Verwandte italienischer Juden, aber auch andere Hilfesuchende, erhielten die rettende Nationalitātsbescheinigung dank geschickter Manipulationen der Konsulatsmatrikel. Geld spielte dabei nur eine sekundāre Rolle, obgleich Generalkonsul Schönberg - der sich, im Gegensatz zur Athener Gesandtschaft, durch penetranten Jagdeifer hervortut - schon bald klagte, mindestens vier "notorisch reiche Juden“ seien von den italienischen Kollegen eingebürgert worden. ${ }^{83}$

Úber die konkrete „Einbuße ${ }^{\mu}$ hinaus fürchtet die Abteilung „Inland II ${ }^{\mu}$ des Auswàrtigen Amts, bei einer Anerkennung solcher Praktiken gefāhrliche Präzedenzfälle zu schaffen, da dann auch andere verbündete oder neutrale Staaten das Recht auf Neueinbürgerung beanspruchen kōnnten. ${ }^{84}$ Heftige Dissonanzen entzünden sich daher bald am Schicksal von 75 bereits zum Abtransport festgesetzten Juden, deren italienische Papiere vom SD angezweifelt werden. In einem Schreiben an das RSHA klagt Thadden über die „sture italienische Haltung “, die auf den griechenfreundlichen Staatssekretār Bastianini zurückgehe. Leider müsse man aber den Wünschen des Achsenpartners nachgeben, da die allgemeine Lage eine Zerreißprobe wegen einiger Dutzend Juden verbiete, darüber hinaus gelte in Griechenland ja immer noch das italienische Primat (preponderanza) - eine Auffassung, der sich auch Weizsācker anschließt. ${ }^{85}$

Von dieser widerwillig tolerierten eigenen Bewegungsfreiheit machen auch die italienischen Militärs eifrig Gebrauch: verschleierte Jüdinnen werden als Offiziersgattinnen ausgeschleust; Verfolgte jeden Geschlechts und Alters werden mit Truppentransporten in die eigene Zone eingeschmuggelt; auch von jenen, die auf eigene Faust die Demarkationslinie überqueren, wird niemand zurückgewiesen. ${ }^{86}$ Es ist nicht mit letzter Sicherheit zu klären, wieviele Juden aus dem „Befehlsbereich Saloniki-Ägäis“ vor dem tōdlichen Zugriff des SD gerettet werden. Einschließlich der 281 „echten“ (bzw. schon frühzeitig anerkannten) Italiener sowie der nahezu 150 ausgeschleusten „Spanier" dürften es $2000-3000$ gewesen sein, die in den Bergen und namentlich in der

81 PAAA, Inland II / 190: Bergmann, Vortragsnotiz 17.3.1943 für RAM (zu D III 399g)

82 PAAA, Pol IV/11, Judenfragen Griechenland I: U.StS.Pol., 345/3.6.1943; vgl. Inland IIg/191: Wisliceny, Brief 21.6.1943.

83 PAA In Inland IIg/190: Schönberg 29-J/1.4.1943. - Tatsīchlich haben die italienischen Konsularbehörden Rückendeckung seitens ihrer Athener Gesandtschaft, die Generalkonsul G. Zamboni bereits am 2.4.1943 ermächtigh, ad agire con criteri larghezza“ - ein Kurs, der wenige Tage später auch von Bastianini abgesegnet wird. (Telegrammtexte in: Carpi, Nuovi Documenti, S. $178 \mathrm{ff}$.)

84 Ebenda: Aufzeichnung von Thadden, Inland II $1071 \mathrm{~g} / 29.4 .1943$.

85 PAAA, Inland IIg/191: Inland II, 1588/4.6.1943; Carpi, Nuovi Documenti, S. 157.

86 Zum gesamten Komplex der italienischen Hilfe: PAM, Inland IIg, fasc. 190 und 191 passim; Carpi, Nuovi Documenti; Molho, In Memoriam I, S. 123 ff.; Léon Poliakov/Jacques Sabille, Gli ebrei sotto l'occupazione Italiane, Milano 1956, S. 159 ff.; Robert Kempner, Eichmann und Komplizen, Zürich 1961, S. 308 ff.; u.ven; ebenfalls: ST-A Berlin 3P(K) Js 10/60, passim, insbesondere Aussagen des it. Konsuls Castrucci und seines Dolmetschers Merci (VI, BI. $140 \mathrm{ff}$; IX, Bl. $256 \mathrm{ff}$ ). In zahireichen Aussagen versucht dabei Merten dazulegen, er habe gegenüber dieser italienischen Praris wohlwollend ein Auge zugedrückt oder sie sogar insgeheim gefördert, was zu einem gewissen Grad, zur eigenen Bereicherung oder als Rückversicherung gedacht, nicht einmal ausgeschlossen ist (Zu Merten vgl. auch Anm. 40, 45 und 97.) 
durch die Kriegswirren noch unübersichtlicher gewordenen Metropole Athen untertauchen $^{87}$; in der Mehrzahl der Fälle spielt der italienische Faktor - durch seine bloße Präsenz - wohl , nur ${ }^{*}$ eine indirekte Rolle.

Der SD, der diese Vorgänge mit kaum verhohlener Wut beobachtet, kann sich jedoch auf einer anderen Ebene für die erlittene Schlappe revanchieren: Heimliche Recherchen gegen den italienischen Oberkommandierenden Geloso enthüllen „skandalöse “ finanzielle und sexuelle Aktivitäten, wobei praktischerweise jüdische Geschäftsleute bzw. Bettgespielinnen als jeweilige Partner des Generals ausgemacht werden. Daraufhin wird Geloso als Chef des Comando Supergrecia untragbar und abgelöst. ${ }^{88}$

Am 9. September 1943 verlieren die Italiener ohnehin ihre inoffizielle Schutzmachtfunktion und benōtigen selbst Hilfe. Stunden nur nach der Bekanntgabe von Badoglios Waffenstillstand mit den Alliierten lāuft die deutscherseits seit Mussolinis Sturz für einen solchen Fall vorbereitete "Aktion Achse ${ }^{\mu}$ an. Die in Griechenland führende Heeresgruppe $E$ entwaffnet die kriegsmüden Bundesgenossen schnell und von wenigen blutigen Ausnahmen abgesehen ${ }^{89}$ - problemlos. Das Ausscheiden der Italiener bedeutet natürlich das Ende der vom SD beklagten "Judenreservate „rechtzeitig“, da man seit Abgang des letzten Deportationszugs im Vormonat zur Untātigkeit verurteilt ist, so daß Wisliceny für einige Wochen gar tatendurstig nach Bratislava geeilt war. Nun trifft er bereits am 20. September in Athen ein, und anderntags lādt er den dortigen Chefrabbiner Barzilai vor, von dem er ultimativ die Bildung eines „Ältestenrats“, aber auch Namenslisten der einheimischen Juden sowie der Flüchtlinge aus anderen Gebieten fordert. Der Rabbi erkennt, daß die bei den ersten diesbezüglichen deutschen Vorstōßen (1941) erprobte Hinhaltetechnik unter den veränderten Umstānden keine Aussichten auf Erfolg bietet. Da er zudem aus dem eigenen Lager bedroht wird, einen ${ }_{n}$ weiten Koretz ${ }^{\mu}$ werde man nicht zulassen, entschließt sich Barzilai zur Flucht in die Berge. Dort bleibt er mit Familie bis zum Kriegsende im Hauptquartier der ELAS-Partisanen.90

Da kurz zuvor, bei einem - übereifrigen griechischen Faschisten zugeschriebenen fingierten Einbruch, vorausblickende Gemeindemitglieder die Matrikel vemichtet hatten, tappen die neuen Herren im Dunkeln, was die Zahl der Gesuchten betrifft. Gemäß einer RSHA-Weisung befiehlt daher Anfang Oktober der eben eingetroffene „Höhere SS- und Polizeiführer" Jürgen Stroop, frisch dekorierter Henker des Warschauer Ghettos ${ }^{91}$, allen (zumindest Dreiviertel-JJuden der nunmehr deutsch okku-

87 Die Schātzungen differieren stark (2.B. Nehama, Israilitiki Koinotis, S. 178; Kabeli, Resistance of Greek Jews, S. 286; diverse Interviews). Ubertrieben ist wohl Mertens Schātzung von 4500, geradezu absurd jedoch der Umstand, daß er sich deren Rettung selbst gutschreiben möchte. (Z.B. Aussage 28.11.1960, in: ST-A Berlin 3P(K) Js 10/60, Bd. V, Bl. $193 \mathrm{ff}$.)

$88 \mathrm{MA}, \mathrm{RW}$ 40/v. 135: Bfh. Südgriechenland $16624 / 43 \mathrm{geh}, 28.5 .1943$; vgl. auch: Ellinikon Aima, 15.5.1943; Akropolis, 11.2.1945.

89 Wichtigste Ausnahme war das Massaker von Kephalonia, wo auf Hitlers persönlichen Befehl wegen des gemeinen und verräterischen Verhaltens" der sich widersetzenden Italiener mehr als 4000 Gefangene brutal liquidiert werden (Fleischer, Kreuzschatten, S. $300 \mathrm{f}$. und $663 \mathrm{f}$.).

90 Nehame, Israilitiki Koinotis, S. 200 ff, vgl. auch S. 183 ff.; PRO, F.O. 371/43690: R 11387. - Zur ELAS vgl. Anm. 100.

91 Stroop selbst rühmte sich, in Warschau Juden, Banditen und Untermenschen vemichtet" zu haben. (Bericht 16.3.1943, zit in: Kempner, Eichmann und Komplizen, S. 324) 
pierten Territorien, sich binnen fünf Tagen registrieren zu lassen. Zugleich ergehen weitere Beschrānkungen wie Umzugsverbot und nāchtliche Ausgangssperre. 92

Unmittelbar darauf wird Stroop jedoch ins Reich versetzt ${ }^{93}$, so daß er nicht mehr selbst auf die weitgehende Mißachtung seines Befehls reagieren kann. Denn trotz der für Ungehorsam angedrohten Todesstrafe melden sich lediglich 200 Juden fristgerecht. ${ }^{94} \mathrm{Da}$ diese nicht behelligt werden und zudem als einzige die existenznotwendigen Lebensmittelcoupons erhalten, treibt der Hunger viele der Illegalen aus ihrem Versteck: bis Mitte Dezember sind bereits 1200 registriert. Doch der SD rechnet fālschlich mit etwa 8000 potentiellen Opfern ${ }^{95}$ - da man viele Flüchtlinge aus dem Norden, die in den Bergen oder gar schon jenseits des Mittelmeers Zuflucht gefunden haben, noch im Untergrund der Millionenstadt vermutet. Bevor daher Wisliceny und Alois Brunner (Referatsleiter IV-B-4 beim Befehlshaber Sicherheitspolizei und SD in Athen) ihre Netze auswerfen, versuchen sie es erneut mit der abgedroschenen und doch immer wieder erfolgreichen Beschwichtigungsstrategie. Abgesehen von einigen minderen wirtschaftlichen Restriktionen sowie den stereotypen antisemitischen Pflichtübungen in Rundfunk und Presse wird der gehetzten Minderheit eine trügerische Verschnaufpause gewährt, wobei man wiederholt eigenes Desinteresse durchblikken läßt. Dennoch ziehen die Angesprochenen - sofem irgendwie möglich - den Schutz der Illegalitāt vor.

Hilfreich erweist sich dabei - weit stärker als in Salonikj96 - die Solidaritāt der christlichen Mitbürger. Ungeachtet der deutscherseits angedrohten drakonischen Strafen wird den Gefährdeten bereitwillig Unterschlupf oder Nahrung gewährt ${ }^{97}$ Beach-

92 Mit Datum 3.10. in der Tagespresse (2.B. Elevtheron Vima, Akropolis) vom 7. und 8.10.1943; vgl. auch: NARS, Washington, RG 226: XI 25080.

93 BDC, Personalakte Stroop: Nachrichtenstelle RFSS, 60/4.10.1943 gKdos.

94 Strvroulakis, in: Sevillias, Athens-Auschwitz, S. XXI; Nehama, Isrilitiki Koinotis, S. 206.

95 MA, RW 40/147: Mbth Gr - Az A 41-25154/43 geh, 18.12.1943.

96 Vgl. hierzu zeitgenōssische jüdische Berichte, z.B.: PRO, F.O. 371/37209: R 13384; F.O. 371/37210: R 13659. - Für die wiederholten antisemitischen Kundgebungen in der mazedonischen Hauptstadt - vom SD mit Befriedigung, von griechischen Autoren peinlich berührt und von den Hauptbetroffenen mit Bitterkeit registriert - hatten rassische oder auch religiöse Gründe nur sekundire Bedeutung. Maßgebend war, daß die Sephardim einen nicht zu assimilierenden kulturellen, habituellen und sprachlichen Fremdkörper sowie von der höchsten bis zur niedrigsten sozialen Ebene einen potenten wirtschaftlichen Konkurrenten darstellten. - Dennoch hält es die Kollaborationspresse für erforderlich, jenen „unpatriotischen“ und „bösen Griechen", die den Juden Hilfe gleich welcher Art leisteten, wiederholt schwere Strafen anzudrohen. Mit sofortiger Einweisung ins KZ wird auch den "vielen Mitbürgern" gedroht, die - unbeeindruckt vom ständig zitierten "historischen Unrecht" der Juden an Griechenland - „aus angeblich philantrophischem Gefühl heraus" jüdische Kinder adoptierten, um sie so dem deutschen Zugriff zu entziehen. (Nea Evropi, $6.3,30.3,31.3,1.4 .1943$ u. $)$ Eine positive Wertung gibt auch die jüdische Gemeinde Salonili in ihrem Exposé zum Holocaust (684/11.6.1945, unveröffentlicht, Kopie im Besitz des Vertassers).

97 Joshua D. Kreindler, Greece and the Jews, in: Joumal of Modern Hellenism 2 (Okt 1985), S. 113-117; Alexandros Kitroeff, Greek Wartime Atritudes towards the Jews in Athens, in: Fonum on the Jewish People, Zionism and Israel 60 (1987), S. 41-51; u.va - Gerade angesichts der Meriten der über weite Passagen faszinierenden Studie von Hannah Arendt (Eichmann in Jerusalem. Ein Bericht von der Banalität des Bōsen, München 1964) sollte es nicht widerspruchslos hingenommen werden, wenn die Autorin - nach einer übertrieben positiven Wertung der bulgarischen Haltung (5.o) - der großen Mehrheit der Griechen Unrecht tut (S. 231): "Die griechische Bevölkerung war bestenfalls indifferent.. Es könnte scheinen, als hätte die Gleichgültigkeit der Griechen gegenüber dem Schicksal ihrer Juden die Befreiung ihres Landes überdau. ert" Im Anschluß an mehrere chronologische Ungenauigkeiten, erweisen sich H. Arendts Informationen aus zweiter oder gar dritter Hand nochmals als unzutreffend, wenn sie - als Indiz für ihre letztzitierte These - schreibt, Merten sei nach dem Kriege, gelassen“ an seinen trüheren griechischen Wirkungsont zurückgekehrt, nwurde verhaftet, kam aber bald wieder frei und konnte nach Deutschland zurückkehren. Sein Fall 
tenswert ist auch die Hilfsbereitschaft der meisten Kollaborationsorgane (mit Ausnahme der auf Kopfgeldbasis arbeitenden „Sicherheitsbataillone"). Eine denkwürdige Rolle spielt namentlich die Polizei unter ihrem - insgeheim mit den Briten und der eigenen Exilregierung kooperierenden - Chef Angelos Evert, der an die 1200 falsche Ausweise ausstellen låßt.98 Ähnliches macht die Kirche in ihrem Bereich: Mit ausdrücklicher Billigung des rührigen Erzbischofs Damaskinos erhalten im ganzen Land Tausende von Juden (zurückdatierte) Taufbescheinigungen; nur ein Bruchteil läßt sich wirklich taufen, da der orthodoxe Klenus keine Proselyten aus Todesangst gewinnen will. 99

$\mathrm{Da}$ indessen die Verfolger die Gefälligkeitsdokumente allzu oft durchschauen, gehen die bedeutendsten Rettungserfolge letzten Endes auf das Konto der Resistance. Ohne dabei die Verdienste kleinerer Organisationen zu schmālern, muß diese Feststellung primär auf die EAM/ELAS 100 bezogen werden, die nicht nur über den effektivsten subversiven Apparat, sondern auch über ausgedehnte Zufluchtstätten verfügte, da sie den Großteil des gebirgigen Landes kontrollierte. Wāhrend die verbliebenen neutralen Diplomaten und selbst die ungarische Gesandtschaft ${ }^{101}$ solche Aktivitāten nach Kräften fördern, erwägen ausgerechnet die Briten, diesen Fluchtweg zu schlieBen, da das Foreign Office eine Stärkung der revolutionāren griechischen Linken durch jüdisches Geld fürchtet. Eine solche Intervention erweist sich jedoch bald als undurchführbar und zudem inopportun. 102

Unter solchen Vorzeichen haben sich bis Mārz 1944 in Athen erst 1500 Juden regi-

ist wohl einzigartig, denn Prozesse gegen Kriegsvertrecher haben in allen Ländem außer Deutschland immer mit schweren Strafen geendet." (Ebenda) - In Wahrheit wurde der einst so,unterschriftsfreudige Kriegsverwaltungsrat auf Grund der aufgefundenen, von ihm unterzeichneten Dokumente in einem aufsehenerregenden Prozeß zu einer 25-jährigen Haftstrafe verurteilt und nur nach massiver Intervention der Bundesregierung abgeschoben - unter der ausdrücklichen Bedingung. daß seine Beteiligung an den Judendeportationen Gegenstand eines deutschen Verfahrens werden müBte. Tatsächlich wurde Merten (1960) bei seiner Landung in Deutschland festgenommen, doch unter wechselnden Auflagen nach elf Tagen wieder auf freien Fuß gesetzt. Die anschließenden langwierigen Ermittlungen brachten außer überquellenden Aktenordnem kein greifbares Ergebnis, ganz wie es die zahlreichen griechischen Kritiker der ungewōhnlichen "Rechtshilfeaktion“ prophezeit hatten. Auf eine knappe Formel gebracht: Alles was man dem - von der prominenten Anwaltskanzlei Heinemann/Posser geschickt verteidigten - Merten an kleineren Verge hen hātte nachweisen kōnnen, fiel unter die Verjährungsfrist und war somit für die justiz irrelevant. $\mathbb{W}_{\text {as }}$ hingegen nicht verjāhrt gewesen wäre, wie etwa Mord oder bewußte Beihilfe zum Völkermord, konnte man ihm nicht nachweisen bzw. glaubte es nicht zu kōnnen. - Die umfangreichen Akten des Ermittlungsverfahrens gegen Merten, Max u.a." (s. Anm. 1) werden übrigens in der vorliegenden Studie wiederholt zitiert.

98 Stavroulakis, in: Sevillias, Athens-Auschwitz, S. XXI; Nehama, Israilitiki Koinotis, S. 210.

99 Ilias Venezis, Archiepiskopos Damaskinos, Athen 19812 ${ }^{2}$ S. 259 ff.; Novitch, Passage des Barbares, S. $115 \mathrm{ff}$;; Kreindler, Greece and the Jews, S. $114 \mathrm{ff}$.

100 Laiki Phoni, 19.7.1942; Rizospastis, 20.4., 10.10.1943; Elevtheri Ellada, 14.10.1943; u.va. - Das „Nationale Volksbefreiungsheer" (ELAS) war der militärische Zweig der "Nationalen Befreiungsfront" (EAM), die zwar von der Kommunistischen Partei kontrolliert wurde, doch aus allen sozialen und politischen Schichten regsten Zulauf hatte. Damit wurde die EAM bald zur größten Organisation, die Griechenland je gekannt hat.

101 Der ungarische Geschäftsträger Laszlo Velics und sein mit einer prominenten linken Griechin verheirateter Erster Gesandtschaftsrat Ivan Bogdan waren klar antideutsch eingestellt, wie aus ihren Berichten nach Budapest hervorgeht (Ungarisches Nationalarchiv, Bestand K 80, Bānde 48/49 sowie K 63, Bānde 110-112; für diesen Hinweis danke ich Dr. Peter Hidas, Dawson College Montreal). In bemerkenswerter Konsequenz flohen Velics „nebst seiner jüdischen Geliebten“ (mittlerweile seiner Gattin?), Bogdan und dessen zur EAM gehörende Frau mit britischer Hilfe im Frühling 1944 nach Kairo. (MA, RH 24-68/36: LXVIII. A.K. Ic, Tagesmeldung 4.5.1944)

102 Auch Churchill widerspricht schließlich dem F.O., allerdings mit einer recht makaber anmutenden Begründung. (PRO, F.O. 371/43689: R 10779, zitiert in: Fleischer, Kreuzschatten, S. 368.) 
strieren lassen. Die Verantwortlichen des SD erkennen, daß mit einer nennenswerten Zunahme nicht zu rechnen ist, zudem stehen sie unter Zeitdruck. Nach Sicherung der technischen Vorbedingungen für den ${ }_{n}$ Abtransport der restlichen Juden vom Festland ${ }^{103}$ wird am 24. März 1944, Vorabend des griechischen Unabhāngigkeitstages, die Falle geschlossen. Mit einem letzten billigen Trick - der Ankündigung, vor dem Passahfest würden Zucker und Mehl zum Matzenbacken verteilt - erreicht man, daß eine überdurchschnittliche Anzahl Juden zum wöchentlichen Zählappell in die Synagoge kommt. Fast 800 werden dort festgenommen, 500 erleiden das gleiche Schicksal in ihren - registrierten - Hāusern. Gemeinsam werden sie für einige Tage im nahen $\mathrm{KZ}$ Chaidari unter menschenunwïrdigen Bedingungen zusammengepfercht ${ }^{104}$, bis auch die Opfer aus der Provinz "transportfertig“ sind.

Zeitlich abgestimmt hatten nämlich auf dem ganzen Festland SD-Jagdkommandos zugeschlagen - mehr oder weniger effektiv unterstützt von der Geheimen Feldpolizei, Wehrmachtseinheiten sowie griechischen Kollaborationsverbānden. Am jeweiligen Ergebnis zeigt sich, inwieweit die Beschwichtigungsparolen der vergangenen Monate auf fruchtbaren Boden gefallen waren, als die deutschen Stellen - direkt oder über den ansonsten gutwilligen Kollaborationspremier Rallis - durchblicken ließen, die mazedonischen Vorkommnisse brauchten die Juden in Altgriechenland nicht zu schrecken. Denn in Saloniki hātte ein geschlossener ethnischer Fremdkōrper - zudem mit subversiven Intentionen - entfernt werden müssen, wohingegen die Gemeinden im übrigen Griechenland fast durchweg aus konservativen und gesetzestreuen Bürgern bestünden, die man als in die griechische Volksgemeinschaft integrierte Gruppe betrachte. ${ }^{105}$ Skepsis hatte dennoch nicht nur in Athen überwogen, sondern in fast noch größerem Ausmaß in den thessalischen Kolonien (Trikala, Larisa, Volos), wo es sich zudem günstig auswirkte, daß keine separaten jüdischen Wohnbezirke existierten. So fiel kaum ein Drittel der Gesuchten den Häschern in die Hānde, während die große Mehrahl, insbesondere die jungen Leute, untertauchte und - meist mit Hilfe der EAM/ELAS - in die Berge flüchtete.

"Erfolgsquoten" von über $90 \%$ erzielt der SD hingegen im relativ isolierten Westteil des Landes (Epirus). Zum ersten ist dort die nationalistische EDES die dominierende Widerstandsorganisation, die gegenüber der jüdischen Minderheit eine - zumindest - zwiespältige Haltung einnimmt ${ }^{106}$ und zudem gerade erst wenige Wochen zuvor ein geheimes Gentlemen's-Agreement mit dem in Westgriechenland führenden deutschen XXII. Armeekorps gegen die „roten Banden“ (ELAS) abgeschlossen hat. 107 Hinzu kommt, daß die epirotischen Juden und namentlich jene der grōßten - nahezu 2000 Seelen zählenden - Gemeinde in Ioannina (Jannina) Graecophone sind und dar-

103 MA, RH 19 VII/16 (Kriegstagebuch Hgr. E), 15.3.1944

104 Sevillias, Athens - Auschwitz, S. 6 ff.; Nehama, Ismilitiki Koinotis, S. 225 ff. - Zur Charakterisierung der Verhältnisse soll bewußt auf griechische Quellen vernichtet werden. Genügend Aufschlüsse gibt wohl ein Auszug aus der Personalakte des Kommandanten: „Primitiv in seinem ganzen Denken und Fühlen, nicht zum Führen geeignet..; offensichtlich einer der alten Schläger, die auf Grund ihrer frühen Zugehörigkeit zur SS zu Führem befördert worden sind"’ (BDC, Akte P. Radomski, Beurteilung 2.12.1944)

105 Rachel Dalven, The Holocaust in Janina, in: J. Modem Greek Studies II: 1 (Mai 1984), S. 91; Nehama, Israilitiki Koinotis, S. 201f. und 229; diverse Interviews.

106 Nach - wohl etwas übertriebenen - deutschen Berichten wird ,aus EDES-Kreisen ... nur volle Zustimmung laut" (2.B. MA, 59644/4: GFP-Gruppe 621, Kdo bei XXII. A.K, 27.3.1944), vgl. hingegen Dalven, Holocaust in Janina, S. 101.

107 Hagen Fleischer, Contacts between German Occupation Authorities and the Major Greek Resistance Organizations, in: latrides, Greece in the 1940s I, S. 48-60 und 347-353. 
aus einen illusionāren Schutz gegen eventuelle Deportationsplāne ableiten. Insonderheit der bejahrte und einflußreiche Präsident von Jannina schenkt den deutschen Versicherungen blinden Glauben und fordert daher bedingungslose Disziplin, zumal er die Vorjahrsereignisse auf das verweltlichte Treiben der Thessalonicher Glaubensgenossen und den daraus resultierenden Gotteszom zurückführt. 108 Negativ wird sich hier jedoch auswirken, daß die janniotischen Juden im Gegensatz zu jenen in Thessalien nicht aufgelockert unter der übrigen Bevölkerung wohnen, sondern seit Menschengedenken in selbstgewählten Ghettos ( ${ }_{n} \mathrm{Ta}$ Ovreika ${ }^{\text {" }}=$ Hebräerviertel), was trotz der gemeinsamen Sprache jede echte Assimilierung verhindert und das Desinteresse vieler christlicher Mitbürger erklärt Unter dem Strich verwundert es nicht, daß die auf das 7. Jahrhundert zurückgehende Kolonie am 25. Mārz 1944 binnen einer Stunde fast ausnahmslos überrascht und, ausgehoben ${ }^{\text {" wird. }}$

Mit dem Erfolg der Gesamtaktion dennoch nur bedingt zufrieden, beeilt sich der SD, die eingebrachte menschliche Beute zu verfrachten: Bereits am 2. April 1944 verläßt ein monströser Transport die Hauptstadt von einem Nebenbahnhof: 1300 in Athen aufgegriffene Juden (darunter eine Anzahl 1943 aus Mazedonien Geflüchteter), dazu die in Preveza, Arta, Agrinion und Patras Festgenommenen. Auf der Fahrt nach Norden werden weitere Gefangene dem ${ }_{n}$ rollenden Alptraum ${ }^{4}$ angegliedert: 90 aus der 2000 Jahre alten Kolonie Chalkis, wo fast drei Viertel der (graecophonen) Romanioten ins umliegende Partisanengebiet entkommen; in Larisa 2400 aus den thessalischen Städten und in erster Linie aus Jannina; in Saloniki schließlich mehrere Hundert Juden, die überwiegend aus der Pelzstadt Kastoria stammen - einer Gemeinde, die ebenfalls schlimmsten Tribut dem Umstand zahlen muß, daß sie sich freiwillig auf wenige ghetto-ähnliche Straßenzüge konzentriert hatte. Nicht alle der annähernd 5000 Verschleppten ${ }^{109}$ landen jedoch in Auschwitz; von den über 80 Waggons des längsten Griechenland je verlassenden Deportationszugs werden die "bequemsten“ ein halbes Dutzend - in Wien abgekoppelt: Uber 150 Juden mit rettender fremder meist spanischer - Staatsbürgerschaft, die trotz der von Graevenitz unterstützten Einsprüche des judenfreundlichen spanischen Generalkonsuls Romero Radigales ebenfalls abtransportiert worden waren ${ }^{110}$, ist ein gnädigeres Schicksal bestimmt. Via Celle gelangen sie am 14. April 1944 nach Bergen-Belsen, wo sie als potentielle „Austauschjuden" den Krieg überleben.111 Ihre nicht-privilegierten Gefāhrten (darunter auch viele Inhaber italienischer Papiere, die seit Badoglios Kapitulation ihren einstigen

108 Daiven, Holocaust in Janina, S. 89; auch: Nehama, Israilitiki Koinotis, S. 230 und 236.

109 Die Teilsummen beruhen v. auf Nehama (Israilitikj Koinotis, S. 227), der insgesamt 5200 bzw. gar 5290 Deportierte errechnet. Graevenitz nennt hingegen „etwas mehr als 5000 Juden“, was er zwei Wochen spāter ausdrücklich als nzu hoch“ korrigiert. Die Gesamtzahl habe „etwa 4700 einschließlich der Ausländer" betragen. (PAAA, Inland IIg/191: Graevenitz $7 / 44$ geh, 3.4.1944 bzw. 7/44 geh. Il, 18.4.1944.) Völlig inadaquat ist diesmal - mit nur 1500 - die Schätzung des Auschwitz-Museums (Czech, Deportation und Vernichtung, S. 24a)

110 Nicht endgültig zu klären ist, ob die überlieferte Zahl von 155 Deportierten nur die Spanier ader sämtliche "Fremdjuden" dieses Transports einschließt. Tatsāchlich nennt Graevenitz (Anm. 109) außer den schließlich nicht deportierten türkischen Staatsbürgern nur 132 spanische, 2 ungarische und „vereinzelt andere Suatsangehörige“" was unter Einschluß der 19 dokumentarisch gesicherten portugiesischen Juden für die zweite Version sprechen würde. Andererseits beziehen Nehama (Istailitiki Koinotis, S. 226), aber auch Avni (Spanish Nationals in Greece), der die Akten des Madrider Außenministeriums ausgewertet hat, die Zahl ausdrücklich nur auf die Spanier.

111 Reitlinger, Endlōsung, S. 429; Nehama, Israilitiki Koinotis, S. 228. - Die 19 portugiesischen Juden hatten Bergen-Belsen bereits im August 1944 verlassen können - offensichtlich da der Druck ihrer „Heimatregierung" stärker war als der der spanischen (Avni, Spanish Nationals in Greece, S. 64) 
Sonderstatus restlos eingebüßt haben) treffen bereits in der Nacht vom 10. zum 11 . April in Auschwitz-Birkenau ein, wo das Gros - etwa $\mathbf{4 0 0 0}$ - unverzüglich ins Gas geschickt wird.

Geschlossene jüdische Kolonien existieren somit nur noch auf einzelnen griechischen Inseln. Nachdem mit der Zuweisung des angeforderten Schiffsraums - seitens der zögernden, letztlich aber doch abermals willigen militärischen Stellen - das stets akute Transportproblem wieder einmal gelöst scheint ${ }^{112}$, kommt zuerst Chania, die mittlerweile einzige ${ }^{113}$ jüdische Gemeinde auf Kreta, an die Reihe. Nachdem der IcDienst der Feldkommandantur 606 bereits seit 1941 "vorgearbeitet“ hatte ${ }^{114}$, wurden im Morgengrauen des 20. Mai, am dritten Jahrestag der Luftlandeoperation "Merkur", annähernd 300 „Israeliten konzentriert, damit sie nach Kontinentaleuropa abgeschoben und dort angesiedelt werden".115 Beim Abtransport auf dem Schiff „Danae“ werden sie jedoch am 8. Juni - zusammen mit 192 anderen (z.T. auch deutschen) Gefangenen - durch Feindeinwirkung versenkt.116 Die Richtigkeit dieser Version darf als gesichert gelten ${ }^{117}$, obwohl bezeichnenderweise auch in diesem Falle vielen eine inszenierte Versenkung wahrscheinlicher erschien. ${ }^{118}$

112 MA, RH 19 VII/17, Bl. 426

113 Nehama (Israilitiki Koinotis, S. 243) behauptet, an 6.6.1943 seien im Zuge deutscher Repressalien auch 800 Juden in Heraklion erschossen worden. Die Zahl ist absurd, denn in Heratlion gab es längst keine jüdische Gemeinde mehr, was alle Quellen (selbst Nehama an anderer Stelle: S. 351 !) bestätigen, sondem lediglich noch 26 Juden (Namensliste vom 20.8.1941 im LAK). Von diesen gelang anscheinend einigen die Flucht nach Nahost, während die Mehrzahl bei zwei Sühneaktionen im Sommer 1943 exekutiert wurde. (Stadt Heraklion (Hrsg.), Ekthesis tis Kentrikis Epitropis Diapistoseos Omotiton en Kriti, Heraklion 1983, S. 42)

114 Befehle zur Registrierung aller Juden, der jüdischen Beamten, Geschäte etc, in LAK, AGSD II; zitiert bzw. Faksimile in: Intemationale Historikerkommission zur Klärung der militärischen Vergangenheit von Kurt Waldheim: Bericht, Wien 1988.

115 Paratiritis (Chania), 21.5.1944. Vgl. auch die zur Schaffung eines antijüdischen Klimas initiierten Hetzartikel vor bzw. nach der Deportation: Paratiritis, 31.3, 5.4, 7.4, 15.4, 23.4, 26.4, 4.5, 28.5.1944. - Was die Zahl der Deportierten betrifft, veranschlagt Nehama (Israilitiki Koinotis, S. 243) - und im Anschluß an ihn andere Autoren - sie auf 260; nur einer Handvoll Juden sei die Flucht gelungen, da die Gemeinde zum Zeitpunkt der deutschen Invasion insgesamt 270 Seelen gezählt habe. Diese Angaben sind jedoch etwas zu niedrig, bzw. läßt die nichtgriechischen Mitglieder unberücksichtigt: Am 14.8.1941 lebten in Chania laut Aufstellung des Rabbiners - 315 Glaubensjuden, davon 44 mit fremder Staatsbürgerschaft. Eine weitere Liste vom 17.2.1943 (beide im LAK) verzeichnet lediglich noch 279 Namen; eine Minderung (um 20) ist insbesondere bei den „Fremdjuden" testzustellen, die offensichtlich z.T. aus ihrem - noch - privilegierten Status Nutzen gezogen haben. Im Mai 1944 bietet jedoch den verbliebenen 24 ausschlieflich italienischen und französischen Staatsbürgern ihr $P_{\mathbf{a}}$ nicht mehr den geringsten Schutz: mit allen anderen chaniotischen Juden werden sie nach Heraklion abtransportiert und mit ihren dortigen Glaubensbrüdem auf den Dampfer „Danae" verfrachtet. Da letztere nach der Dezimierung im Jahr zuvor höchstens noch auf ein knappes Dutzend zu beziffern sind, ist die Gesamtzahl der sistierten (und dann ertrunkenen) kretischen Juden unter $\mathbf{3 0 0}$ anzusetzen; die entsprechende Angabe im Kriegstagebuch der Heeresgruppe E (MA, RH 19 VII/17, Bl. 550) dürfte also aufgerundet sein.

116 MA, RH 19 VII/17, BI. 550; PAAA (vgl. Anm. 60), Sonderbevollmāchtigter für den Südosten, Dienststelle Athen, Bd. II: Pol. 4/4, Nr. 2598/44, 28.6.1944. Nicht völlig geklärt ist jedoch, ob die "Danae" - wie von der Hgr. E vermutet - torpediert wurde oder ob sie auf eine Mine auflief. Eine bewußte Versenkung durch die Alliierten wäre nämlich befremdlich, da die Deutschen zuvor die "Ladung" absichtlich im unverschlüsselten Funkverkehr durchgegeben hatten, da die Marine daran interessiert war, die "Danae", eines ihrer letzten verfügbaren Schiffe, unversehrt nach Piräus durchzubringen. (Interview H. Kölle, Leiter der Marinewetterwarte Chania, in: Marlen v. Xylander, Die Deutsche Besatzungsherrschaft auf Kreta 1941-1945, Freiburg 1989, S. 122); s. auch: Eberhard Rondholz, in: Die Zeit, 20.11.1987.

117 Ebenda; To Vima, 2.2.1960. - Die Abc. Inland schlug daher bald vor, „die Tatsache der Vernichtung mehrerer Hundert Juden durch den Gegner propagandistisch auszuwerten“. (PAAA, Inland II A/B-64/3: Inl. ILA 2303, 10.7.1944.)

118 Nehama, Israilitiki Koinotis, S. 244; Novitch, Passage des Barbares, S. 109; E. Petrakis, I Ethniki Organosis Kritis (EOK) kata tin Germaniki Katochin, Heraklion 1953, S. 56; u.2. 
Die nāchste Station der Eichmann-Emissāre sind die beiden Gemeinden auf den Ionischen Inseln. Die kleinere wird dabei auf unerwartete Weise nicht nur in die griechischen Annalen eingehen: als einsames Beispiel, was - zumindest unter günstigen Voraussetzungen - Zivilcourage und Solidaritāt vermögen. A. Lüth (oder Lütt), der offensichtlich regimekritisch eingestellte deutsche Kommandant von Zakynthos (Zante), außert nāmlich ernste Bedenken gegen eine Deportation der 275 Juden in seinem Befehlsbereich: Da sie fast ausnahmslos mit der griechischen Inselbevölkerung befreundet und verschwägert seien, würde diese in einem solchen Fall äußerst erbittert reagieren - eine Einstellung, die von den lokalen griechischen Behörden wie auch dem Metropoliten vorbehaltlos geteilt werde. Auch ließe sich keinerlei ${ }_{n}$ antiplutokratischer" Unmut aktivieren, da die Betroffenen fast durchweg den ārmeren Schichten angehörten und auch sonst ${ }_{n}$ keine Gefahr" darstellten. Die auf dieser Argumentation basierende Verschleppungstaktik des Offiziers, verbunden mit der tatkräftigen Solidaritāt der Insulaner, rettet die kleine Gemeinde schließlich bis zum deutschen Abzug. ${ }^{119}$

Mit ähnlichen Vorbehalten operiert anfangs auch der vermutlich geistesverwandte Inselkommandant Jāger auf Kerkyra (Korfu).120 Doch dort ist die jüdische Kolonie mit nahezu 2000 Mitgliedern weit stārker, spielt wirtschaftlich eine herausragende Rolle, hat eine fremde Muttersprache (Italienisch) und siedelt seit mehr als einem halben Jahrtausend in einem abgesonderten Viertel - alles Faktoren, die einem größeren Engagement der orthodoxen Korfioten entgegenstehen. Den Experten des SD - den schon mehrfach „bewāhrten“ Burger und Linnemann unter tatkräftiger Unterstützung des sprachkundigen jüdischen Renegaten Rekanatis - gelingt es sogar, den „Pöbel“ in großem Umfang für antisemitische Ausschreitungen zu gewinnen. ${ }^{121}$ Die Beihilfe des Ic-Dienstes bzw. der Geheimen Feldpolizei ist auch hier übrigens mehrfach dokumentiert. ${ }^{122}$ Die 1795 am 9. Juni Verhafteten werden in die Hauptstadt abtransportiert und von dort zusammen mit den "Restjuden “ aus dem KZ Chaidari - der "Aus-

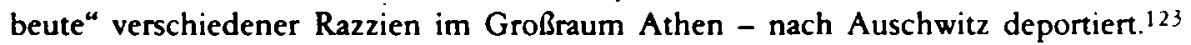

Im Monat darauf, wāhrend die antisemitische Propaganda einen weiteren Paroxysmus verzeichnet ${ }^{124}$, schlägt die Stunde auch für die dodekanesischen Sephardim, de-

119 Nehama, Israilitiki Koinotis, S. 247 ft. - Molho (In Memoriam I, S. 107) nennt noch einen Ausnahmefall ${ }^{4}$ eines „anständigen“ deutschen Offiziers, den Kommandanten der mazedonischen Mittelstadt Katerini, der im März 1943 bewußt die Augen schließt, als - unter Mitwirkung des Chefs der lokalen griechischen Polizei - 30 der 33 ortsansässigen Juden untertauchen. (Vgl., ohne Nennung des Deutschen: Roth, Last Days, S. 54)

120 Jäger schlägt vor, zur Vermeidung von Unruhen unter den Korfioten die Deportation der Inseljuden nauf unbestimmte Zeit zu verschieben“. Zudem würde die geplante Aktion für die deutsche Sache zwangslāu$\mathrm{fig}_{n}$ ethischen Prestigeverlust in den Augen der Bevölkerung “ mit sich bringen, $n$ weil die unvermeidlichen Brutalitāten nur abstoßend wirken könnten“! (MA, 59644/4: Inselkdt. Korfu, 378/44 geh., 14.5.1944.)

121 Der führende Lokalhistoriker spricht deswegen von neiner der traurigsten Seiten in der Geschichte Kerkyras". (K. Daphnis, Chronia polemou kai katochis: Kerkyra 1940-1944, Kerkyra 1966, S. 292 f.) - Zur Aktion vgl. auch Rekanatis‘ Aussage in: 29 Js 1/70: Bd. III, Bl. 474 tf., u.a.; zum ProzeB gegen R. und andere jüdische Renegaten: Evraiki Estia, 4.7.1947.

122 "Waldheim-Report" (Anm. 114), Kapitel VI passim.

$123 \mathrm{MA}, 59644 / 4: B f h$. SiPo/SD für Griechenland, Außendienststelle Jannina IVB, 17.6.1944; Nehama, Israilitiki Koinotis, S. $246 \mathrm{t}$.; Novitch, Passage des Barbares, S. $101 \mathrm{ff}$.

124 NARS, RG 59: US Consulate Istanbul, 25.8.1944: Trends in Enemy Propaganda Conceming Greece. 
ren Zahl von 10000 Seelen zu Beginn des Jahrhunderts 1940 bereits auf knapp 2000 abgesunken war. Das Trio Burger-Linnemann-Rekanatis fliegt im Juli nach Rhodos, wo sie binnen weniger Tage emeut das bereits zu makabrer Routine erstarrte Drama inszenieren. Wenigen nur gelingt es unterzutauchen; über 50 türkische Staatsangehörige - darunter auch einige „unklare“ Fälle - werden dank des persönlichen Einsatzes des Konsuls Ulkumen von der Deportation ausgenommen. ${ }^{125}$ Dagegen werden 1673 Juden am 24. Juli nach Athen verschifft, hinzu kommen mindestens 83 von der Nachbarinsel Kos. ${ }^{126}$ Nach einem kurzen und leidvollen $Z$ wischenaufenthalt in Chaidari geht der Transport Anfang August weiter nach Auschwitz; ein Waggon mit 90 in den Vorwochen eingefangenen Athener Leidensgenosen wird angekoppelt. ${ }^{127}$

Zu einem Zeitpunkt, als die Rote Armee sich anschickt, die südöstlichen Achsensatelliten wie Dominosteine der Reihe nach umzukippen, während die Heeresgruppe E bereits erste Evakuierungsvorbereitungen trifft, wobei zwangsläufig wertvollstes Heeresgut auf der Halbinsel zurückbleibt, spricht diese Vergeudung von knappstem Transportraum auf der einzigen, ohnehin überlasteten Rückzugslinie jeder strategischen Uberlegung Hohn: „Aber gleich einem Zug blinder Raupen unterwarf sich die Wehrmacht der Allgewalt des Führerbefehls. ${ }^{\text {"128 }}$

Diese wahnwitzige Aktion ist endgültig die letzte Deportation von griechischem Boden. Zwar werden auch in den nächsten Wochen noch einige flüchtige Juden ergriffen, doch ist an einen Abtransport nicht mehr zu denken, da noch im selben Monat, nach dem Zusammenbruch des Antonescu-Regimes in Rumānien, die Räumung Griechenlands - wenn auch „unter Wahrung strengster Tarnung “ - endgültig eingeleitet wird. ${ }^{129}$ Dennoch werden in Saloniki noch am 8. September 1944 acht von dreizehn sistierten Juden exekutiert ${ }^{130}$, und das gleiche Schicksal droht den Häftlingen im attischen KZ Chaidari, namentlich den 30 Juden mit griechischer Staatsbürgerschaft. Doch der Militärbefehlshaber Felmy hebt den Exekutionsbefehl des abrückenden SD auf und läßt jene ebenso frei131 wie ihre bereits seit Monaten intemierten, doch von

12529 Js 1/70, Bd. I, Bl. 176f.; Hizkia Franco, Les Martyrs Juits de Rhodes et de Cos, Elizabethville 1952, S. 99; Novitch, Passage des Barbares, S. 109.

126 Reitlingers (Endlösung, S. 429) Ziffer 1200 ist zu niedrig, und er irrt sich, wenn er dabei „eine bedeutsame Ubereinstimmung in den Schātzungen" festrustellen glaubt. Stattdessen Details und Namensliste in: Franco, Les Martyrs Juifs, S. $119 \mathrm{f}$. und $122 \mathrm{ff}$. Dieser Quelle zufolge überteben 163 Dodekanesier Auschwitz (S. 165). Ebenfalls: Novitch, Passage des Barbares, S. 105 ff.; 29 Js 1/70, Bd. I-III, passim; Edoardo Fino, La Tragedia di Rodi e dell Egeo, Rom 1957, S. 250 ff. Die Ankunft der Rhodier in Athen/Chaidari bzw. Auschwitz widerlegt diesmal zweifelsfrei die These von der absichtlichen Versenkung der Judenbarken“ durch die Begleitmannschaften. Der Zeuge E.L, der diese Version der US-Anklagebehōrde in Nürnberg unterbreitete, „erginzt" diese anderthalb Jahrzehnte später noch durch die Behauptung, er habe die Versenkungsaktion mit eigenen Augen beobachtet. (29 Js 1/70, Bd. II, Bl. 349 ff.; Bd. IV, Bl. 591 ff.; vgl. auch: Reitlinger, Endlōsung, S. 430). - Zur Judenaktion" auf Kos (mit etwas abweichenden Zahlen) s.: Chronika (Athen), Sept 1987, S. 11 f. - Vgl. auch die etwas niedrigeren Zahlen im Beitrag zu Italien in diesem Band, Tabelle 6.

127 Nehama, Israilitiki Koinotis, S. 252; vgl. auch: Die Odyssee der Frauen von Rhodos, in: Dachauer Hefte 3 (1987), S. 158-165.

128 Reitlinger, Endlösung, S. 430.

129 MA, RH 19 VII/25, Bl. 871 f. (29.8.1944)

130 Namen in: Matarasso, Ki'omos, S. $61 \mathrm{ff}$.

131 Matarasso, Ki'omos, S. 63; Nehama, Israilitiki Koinotis, S. 252; vgl. auch: Roland Hampe, Die Rettung Athens im Oktober 1944, Wiesbaden 1955, S. 24 und 29. 
der Deportation verschont gebliebenen argentinischen ${ }^{132}$ und türkischen ${ }^{133}$ Glaubensgenossen.

Im Rahmen dieser Untersuchung erübrigt es sich, detailliert auf das Schicksal jener Unglücklichen einzugehen, die den langen Weg nach Auschwitz antraten. ${ }^{134}$ Für die meisten - über drei Viertel - erfüllte sich dieses Schicksal ohnehin sogleich nach der Ankunft in der Todesfabrik. Jene 12 757, die die Selektion an der Rampe vorerst überleben, trifft ein Geschick, das in manchen Aspekten noch härter ist, als das der Leidensgefährten aus anderen Ländem. Nicht nur das für Südländer besonders ungewohnte rauhe Klima trägt hierzu bei, sondern auch die Isolierung als Folge von Verständigungsschwierigkeiten: die meisten griechischen Juden - selbst viele Mehrsprachige (mit Spaniolisch, Griechisch, Italienisch oder auch Franzōsisch) - beherrschen keine der im Lager dominierenden Sprachen (slawische bzw. Deutsch und Jiddisch). ${ }^{135}$ Zahlreiche Opfer fordert eine eingeschleppte Flecktyphus-Epidemie. Ein relativ hoher Prozentsatz namentlich der Frauen wird zu pseudo-medizinischen Versuchen abgestellt. Juden aus Saloniki - spāter aus Preveza und Athen - bemannen die "Sonderkommandos“; wiederholt kommt es zu - blutig geahndeten - Rebellionen. 136 Úber 1500 mazedonische Juden werden im Spätsommer und Herbst 1943 zum Arbeitseinsatz ins zerstörte Warschauer Ghetto geschickt. Viele sterben an den Strapazen, andere werden von polnischen Partisanen befreit - zwei überleben; 41 Kranke werden bei der deutschen Evakuierung zurückgelassen - vier überleben; 450 werden

132 Argentinien, nach dem Ausbruch des deutsch-griechischen Krieges Schutzmacht für Griechenland, versucht 1942/43 wiederholt, wenn auch vergeblich, diese Funktion auch auf die griechischen Juden - selbst in anderen deutschokkupierten Lindem und im Reich selbst! - auszudehnen. (2.B. PAAA, Inland Il A/B64/3: Pausch, Inl. II A 2752/12.4.1943.) In einer AA-intemen Notiz wird daraufhin resümiert „die im Deutschen Reich befindlichen griechischen Staatsangehörigen werden nicht wie feindliche Ausländer behandel, sondern sind lediglich den üblichen, für Ausländer geltenden Bestimmungen unterworfen", hingegen sei mit den im Reich befindlichen griechischen Juden gleichermaßen zu verfahren wie mit den deutschen, „d.h. sie unterliegen grundsaitzlich der Kennzeichnung und späteren Abschiebung nach dem Osten u. s. w." (sic! Hervorhebung durch den Verfasser) Es sei jedoch ratsam", die argentinische Schutzmacht hierüber mōglichst im Unklaren zu lassen. (PAAA, Pol IV, Griechenland 3-4/43, B1. 3) Zumindest aber den 19 "nichtarischen argentinischen Statsbürgern" im Athener Raum wird ein privilegierter Status zuerkannt, bis sie Ende Januar 1944 in einer Blitzaktion verhaftet werden - unmittelbar nachdem Buenos Aires die Beziehungen zum Reich abbricht. Aus Sorge um die zahlreichen Deutschen in Argentinien wagt der SD dennoch keine weitergehenden Maßnahmen. (u.a. P.K. Enepekides, Oi diogmoi ton Evraion en Elladi 1941-1944, Athen 1969, S. 117 ff.; s. auch Anm. 30.)

$133 \mathrm{Im}$ Februar/Mär 1944 waren von den insgesamt 72 türkischen Juden in Athen bereits 32 nauf normalem Weg in die Türkei rückbefördert worden". Die restlichen $\mathbf{4 0}$ werden zwar im Laufe der Großrazzia verhaftet, auf Drängen des türkischen Generalkonsulats aber für einen Sammeltransport in die (meist nur nominelle) Heimat freigegeben. (PAAA, Inland $I_{g} / 191$ : Graevenitz 7/44 geh., 3.4.1944).

134 Die wichtigsten Berichte Ubertebender sind: Sevillias, Athens - Auschwitz; Heinz S. Kounio (Cougno), Ezisa to thanato, Saloniki 1981; Abert Menasche, Birkenau. How 72.000 Greek Jews Perished, New York 1947 (griech. Version: Saloniki 1974); Markos Nachon, Birkenau, in: Evraiki Estia, 19.8.1949-28.4.1950; außerdem die Ubersichtswerke von Nehama, Israilitiki Koinotis, und Matarasso, Ki'omos.

135 Vgl. hierzu: Filip Friedman, This was Oswiecim, London 1946, S. 69 f.: „The Greek Jews were among the worst-treated elements in the camp."

136 Eine Gruppe weigert sich, ihren "Dienst“ anzutreten und wird geschlossen am gleichen Tag (22.7.1944) vergast. (Vgl. Czech, Deportation, S. 34; Nehama, Israilitiki Koinotis, S. 303). Nicht unumstritten ist der griechische Part an der großen Revolte im Oktober 1944. Die Angaben schwanken je nach Nationalität des Verfassers. - Zum gesamten Komplex des griechischen Widerstands vgl. den - leider oft übertreibenden - Artikel von Kabeli, Resistance of Greek Jews. 
mitgenommen - eine Handvoll erlebt die Ankunft im āltesten deutschen $\mathrm{KZ}$, in Dachau. ${ }^{137}$

Damit ist es an der Zeit, Bilanz zu ziehen. Griechenland in den heutigen Grenzen also einschließlich des damals italienischen Dodekanes sowie der von Bulgarien de facto annektierten Ostgebiete - war am Vorabend der deutschen Besetzung Heimstātte für über 70000 (Glaubens-)Juden. Vor dem Beginn der eigentlichen Deportationen im März 1943 kann man - trotz z.T. kursierender hōherer Zahlen - einen Sterbeüberschuß von 1500 über die ,natürlichen “ Todesfälle hinaus annehmen. Hauptursachen sind neben den direkten Kriegsauswirkungen (Fronteinsatz, Bombardienungen) die Hungersnot (mit ihrem Hōhepunkt im Winter 1941/42), Exekutionen als „Strafund Sühnemaßnahmen“ sowie Seuchen und Auszehrung als Folge der Zwangsarbeit. Bis zur Befreiung fallen noch Hunderte diesen Umständen zum Opfer, doch dürfte die Gesamtziffer dieser Kategorie 2500 kaum überschreiten, wobei auch die ertrunkenen kretischen Juden eingeschlossen sind.

Recht genau einzugrenzen sind die Verluste in der bulgarischen Zone. Nur wenige entkommen dank irgendwelcher rettender Zufälle, annähernd $\mathbf{4 2 0 0}$ werden verhaftet und nach Treblinka deportiert. Kein einziger kehrt zurück.

In der deutschen Zone werden bis zur italienischen Kapitulation 18 Transporte nach Auschwitz durchgepeitscht, für die eine Addition der zuverlāssigen Zahlen 45123 Deportierte ergibt ${ }^{138}$ Diese Zahl erhöht sich zwischen April und August 1944, mit den drei Transporten aus der ehemals italienischen Zone, auf 53789 - was der Zusammenstellung des Auschwitz-Museums nahekommt.139 Uber 40000 Frauen, Kinder und Mānner fallen sofort der Selektion zum Opfer, lediglich 8025 männliche

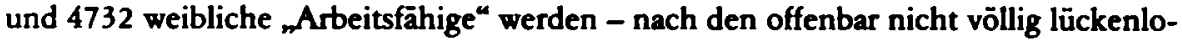

137 Menasche, Birkenau (griech. Ausgabe) S. 931 f; Nehama, Isrilitiki Koinotis, S. 279f. - Ende April 1945 waren im KL Dachau insgesamt 338 Griechen inhaftiert, devon 158 Juden. (Barbara Distel, KZ-Gedenkstintte Dechau: Archiv, Brief 9.8.1984; baw. Katalog Konzentrationslager Dachau 1933-1945, 19786: Dok. 438/452).

138 Für die ersten 16 Transporte existieren Unterlagen der Direktion Griechischer Stantsbahnen, die auf eine Summe von 42300 Deportierten kommen (abgedruckt in Matarnso, Kiomos, S. 55). Diese Ziffer düfte weitgehend korrekt sein, was nicht unbedingt immer für die תunden" Zahlen der Einzeltransporte gilt, da es oft im letzten Moment Verschiebungen gab, die primär von der Menge des verfügbaren rollenden Materials (und weniger des „Menschenmaterials) abhingen. - Zu erwihnen ist hier, da B im Magazin der Bahnstation Auschwitz insgesamt 30783 "Kontrollmarken“ dieser Sammeltransporte gefunden wurden (Czech, Deportation, S. 22). Aus den ethaltenen Nummem läßt sich eine whrscheinliche Gesamtzahl von 41970 - 42870 errechnen (Nummern 3000-4000, $4901-5000$ (oder 4001-5000), ca 14400 - ca 55 269). Es muß technische Gründe (oder Irrtümer) dafür gegeben haben, die fehlenden Nummern zu überspringen brw. ungebraucht zu vernichten. Mit zusätzlichen (und infolge Totalvernichtung nicht von der Evidenz erfaßten) Transporten sind die verbliebenen Lücken nicht zu erklären. Dagegen spricht nicht nur die Quellenlage sowie die Zahl der verhafteten (und vorhandenen) Juden, sondern auch die Tatsache, daß die Kontrollmarken offenbar zur Kostenberechnung dienten (Czech, Deportation, S. 23) demnach also alle wirtlich ausgegebenen von der griechischen Bahndirektion berücksichtigt wurden. - Der Vf. schlietlich kommt durch Addition der wahrscheinlichsten Zahlen für die 16 ersten Einzeltransporte auf 42503 Verschleppte, die zusammen mit den recht präzisen Angaben für den 17. und 18. Transport die genannte Zwischensumme von 45123 ergeben.

139 Czech (Deportation, S. 24a) errechnet 54523 Deportierte, wobei ihre Unterlagen („Kalendarium”, s. auch Kounio, Exisa to thanato, S. 247 ff.) allendings wiederholt ungenau sind. So wird beispielsweise der Transport vom 9.5.1943 (Ankunft 16.5.), der mit ca. 1800 zu den kleinsten gehört, auf 4500 beziffert und damit als größter eingestuft. Auch Fehler mit umgekehrter Tendenz kommen vor (vgl. va 2/11.4.1944 - Anm. 109). 
sen Auschwitzer Unterlagen - in die Evidenz eingetragen und ins Lager eingeleitet. ${ }^{140}$ Am 2. September 1944 leben noch 1738 Männer und 731 Frauen ${ }^{141}$ - wobei es nicht völlig geklärt ist, ob die Dodekanesier hierin enthalten sind. Diese Zahl wird sich noch weiter drastisch verringern, wozu insbesondere die furchtbare Evakuierungsaktion ab Januar 1945 beitragen wird. 142 Nicht enthalten in der obigen „Bestandsaufnahme ${ }^{*}$ sind hingegen die Uberlebenden ihrer in den Vormonaten nach Warschau oder anderswohin zum Arbeitseinsatz abgestellten Landsleute.

Was die Gesamtzahl der Uberlebenden betrifft, stimmen fast alle Berichte darin überein, daß insgesamt etwa 1800 - 2000 Deportierte nach Griechenland zurückkehrten; zumindest in der höheren Zahl sind auch die ca. 150 dodekanesischen Juden enthalten, die nach der Befreiung zuerst nach Italien, ihrem offiziellen Heimatland, geschickt worden waren ${ }^{143}$, ferner wohl auch jene der zusammen 522 "Spanier ${ }^{*}$ aus Bergen-Belsen, die direkt oder auf Umwegen zumindest vorübergehend wieder nach Griechenland kommen. ${ }^{144}$ Von den 74 privilegierten griechischen Staatsbürgem, die im gleichen Lager interniert sind, fallen einige Krankheiten zum Opfer. Stunden nur nach der Befreiung stirbt auch Chefrabbiner Koretz - der offiziellen Lesart zufolge an Typhus, tatsächlich wird er aber wohl von empörten Landsleuten gelyncht. ${ }^{145}$ Die

140 Laut Czech (Deportation, S. 25) ist an dieser Gesamtzahl von 12057 „nicht zu zweifeln“. In der einschlägigen Literatur (2.B. Nehama, Israilitiki Koinotis, S. 228 und 480; Sevillias, Athens - Auschwitz, S. 99; Menasche, Birkenau (gr.), S. $18 \mathrm{f}$.) werden allerdings z.T. höhere Teilsummen genannt, und während Czech beim Kortu-Transport die weiblichen Lagernummern von $\Lambda 8282$ bis $\Lambda 8412$ angibt, publiziert Novitch (Passage des Barbares, S. 102 und 104) die Aussagen der Ex-Häftlinge $\Lambda 8418$ und $\Lambda 8421$. Darüber hinaus hat der Verfasser nach Abschluß dieser Studie (1988, anläflich seiner Beteiligung in der sog. "WaldheimKommission”) Einblick in sonst unzugängliche griechische Akten erhalten. Darunter war eine detaillierte Liste mit medizinischen Untersuchungsergebnissen der ersten $172 \mathrm{KZ}$-Heimkehrer. In dieser Ubersicht sind 2.B. zwei überlebende Juden aus Kastoria enthalten, die im April 1944 nach Auschwitz transportien wurden und dort die Nummern 182002 bzw. 182065 erhielten. Das steht im Widerspruch mit Czech, die lediglich 182440 - 182759 als Nummem der registrierten, da ins Lager eingeleiteten Männer dieses Mammuttransports nennt. $Z u$ diesen 320 Männem, die nicht sofort ins Gas geschickt wurden, sind also mindestens 63, wenn nicht gar 438 oder mehr zu addieren. Weiterhin konnte festgestellt werden, daß fünf der überiebenden Frauen des letzten Transports (August 1944) bei ihrer Ankunft in Auschwitz die Nummern 77030, 77037, 77098, 77154 und 77155 eintätowiert wurden. Unter Einschluß der „Zwischennummem" (die jedoch nicht überlebten oder vielleicht z.T. erst später heimkehrten), überstanden also zumindest 126 weitere Frauen (über die von Czech genannte Nummernreihe A 24215 - A 24468 hinaus) die Erstselektion. Um jedoch keine Mißverständnisse auflommen zu lassen, sind in diesem Zusammenhang zwei Punkte zu unterstreichen: 1) Die festgestellten Lücken in den Unterlagen des Auschwitz-Museums betreffen ausnahmslos die drei letzten (Athener) Transporte. 2) An der Gesamtzahl der Opfer (bzw. der Deportierten und der letztlich Uberlebenden sowie natürlich deren Differenz) ändert sich dadurch nichts, lediglich der Zeitpunkt des gewaltsamen Todes einiger Hundert Menschen verschob sich um wenige Wochen oder bestenfalls Monate.

141 Czech, Deportation, S. 34. - Vermutlich wurden die Dodekanesier in dieser Statistik zu den Italienem gerechnet, da Nehama (Isrilitiki Koinotis, S. 312) im Januar 1945 noch 3000 griechische Juden annimms die Ausch vitz vor der heranrückenden Roten Armee verlassen müssen.

142 Nehams, Israilitiki Koinotis, S. 312 ff; insgesamt schätzt der Autor (S. 293) die bei Nachselektionen Vernichteten auf über 7000, die an Strapazen, Krankheiten etc. Zugrundegegangenen auf 3000.

143 Nehama, Israilitiki Koinotis, S. 347 und 349; ua - Reitlinger (Endlösung, S. 404 und 565) nennt 146 Dodekanesier, tatsāchlich überieben mindestens 163 (Franco, Les Martyrs Juifs, S. 119f. und 165), doch kehren manche nicht zurück, sondem zichen eine direkte Uberfahrt nach Palästina etc. vor.

144 Im Gegensatz zu der Anfang 1944 nach Palästina evakuierten Thessalonicher Gruppe bleiben die (155?) Nachzügler aus Athen, wie erwähnt, bis zur letzten Phase des Zusammenbruchs in Bergen-Belsen und kehren schließlich erst im Spätsommer 1945 heim. Bald darauf setzen beiderseits des Mittelmeers in den jeweiligen Gruppen konträr verlaufende Migrationsbewegungen ein, die ein weiteres Mal präzise statistische Angaben verhindem.

145 Matarasso, Ki'omos, S. 50; bzw. Interview Estrongo Nachama 
übrigen „Prominenten“ treffen im September 1945 wieder in Mazedonien ein, einige werden allerdings wegen Kollaboration mit dem Feind zu Haftstrafen verurteilt.

Von den ca. 58585 nach Auschwitz, Treblinka und Bergen-Belsen verschleppten griechischen Juden kehren also bis Ende 1945 etwa 2000 Uberlebende in ihre alte Heimat zurück, wohingegen mindestens 200 mit spanischen Papieren nach Palästina überführte Gefāhrten es vorziehen, dort zu bleiben oder in Drittlānder überzusiedeln. Somit läßt sich eine Zahl von 56385 Opfern errechnen, die - fast ausschließlich in den beiden erstgenannten Lagern - ermordet, z.T. aber auch einem langsamen Tod ausgesetzt wurden. Zusammen mit den im Inland aus ${ }_{n}$ kriegs- und okkupationsimmanenten " Ursachen Verstorbenen und Getöteten (2500) ergäbe das eine Gesamtverlustzahl von 58885 Juden.

Auf über 8500 beläuft sich die Zahl der Juden, die die Besatzungsjahre auf griechischem Boden überleben ${ }^{146}$ - davon nur wenige Hundert „legal ${ }^{\text {" }}$ : dank einer neutralen Schutzmacht (Türkei, Argentinien) oder, häufiger, eines „arischen “ Ehepartners. ${ }^{47}$ Die überwältigende Mehrheit hingegen taucht erst nach dem deutschen Abzug wieder aus dem Zwielicht der Illegalitāt auf. Ende Dezember 1945 werden vom nIsraelitischen Zentralrat" in Griechenland insgesamt 10226 Juden registriert; die Zahl jener, die sich aus dem einen oder anderen Grund nicht melden, wird auf $200-400$ geschätzt. ${ }^{148}$ Unter den Registrierten sind höchstwahrscheinlich auch die beiden Auswanderertransporte eingeschlossen, die zu diesem Zeitpunkt das Land bereits in Richtung Palästina verlassen haben. 149

Nicht berücksichtigt ${ }^{150}$ sind hingegen jene, die schon während der Okkupationszeit nach Nahost geflüchtet waren - eine Kategorie, bei der die Schātzungen weit auseinandergehen: die der zuverlässigsten Autoren liegen bei 1500 bzw. 3000.151 In der vorliegenden Untersuchung soll daher ein ungefährer Mittelwert von 2000 benutzt werden, der auch mit verschiedenen anderen Indizien 152 in Einklang zu stehen scheint. Im Rahmen der Gesamtbilanz bedeutet das allerdings, daß entweder die Zahl der Ver-

146 Akropolis, 22.5.1945; u.2

147 Nehama, Israilitiki Koinotis, S. 211; Matarasso, Kiomos, S. 52; Tamir, Bulgaria and Her Jews, S. 293. - Die Befreiung für Mischehenpartner galt in allen Zonen, doch nur ,für die Dauer dieser Ehe“...

148 Matarasso, Kjomos, S. 561 .; eine andere Quelle nennt - für Dez. 1945 - 9825 Juden, worin allerdings die Uberiebenden einiger kleiner Gemeinden nicht erfaßt sind. (Leon Shapiro/Joshua Starr, Recent Population Data Regarding the Jews in Europe, in: Jewish Social Studies 1 (1946), S. 86.

149 Einem legalen "Exodus" mit 210, folgt ein ungenehmigter mit 212 Teilnehmem, die zwar auch glücklich die palästinische Küste erreichen, wobei allerdings acht Fluchthelfer durch britische Patrouillen den Tod finden. Insgesamt 253 der Immigranten waren übrigens KZ-Heimkehrer. (Lehrman, Greece, S. 52; Shapiro/Star, Recent Population, S. 86)

150 Auch in verschiedenen einschlägigen Untersuchungen werden die Nahostflüchtlinge zwar z.T. im Text erwähnt, bei den abschließenden Statistiken aber unberücksichtigt gelassen. Um die Zahl der Opfer zu erhalten, wird dann vereinfachend die Zahl 10226 von einer der kursierenden Schätzungen des Vorkriegsstands abgezogen.

151 Nehama, Israilitiki Koinotis, S. 216 (im Vergleich mit S. 335 des gleichen Autors scheint die Schätzung von 1500 zu niedrig); hingegen wohl überhöht: Bowman, Jews in Wartime Greece (3000). - EinzuschlieBen in diese Kategorien wären auch einige Dutzend türkische Staatsangehōrige, die nach der Befreiung nicht zurückkehren.

152 Dazu gehören auch die zahlreichen Vernehmungsprotokolle von Flüchtlingen im US-Konsulat von Istanbul (NARS, RG 59, passim). Einige der Aussagen wurden mittlerweile veröffentlicht: Alexandros Kitroeff (Hrsg.h Documents: The Jews in Greece, 1941-1944 - Eyewitness Accounts, in: Journal of the Hellenic Diespora 3 (1985), S. 5-32. 
schleppten/Ermordeten um ein Geringes niedriger anzusetzen ist ${ }^{153}$ und/oder - wahrscheinlicher - die gesicherte“ Ausgangszahl vor dem deutschen Einmarsch etwas erhöht werden muß.

Getörete und überlebende Juden 1941-1945

\begin{tabular}{|c|c|}
\hline $\begin{array}{r}52185 \\
4200 \\
2500\end{array}$ & $\begin{array}{l}\text { Opfer von Auschwitz (deutsche Zone) } \\
\text { Opfer von Treblinka (bulgarische Zone) } \\
\text { Exekutionen und andere okkupationsbedingte } \\
\text { Todesfälle innerhalb Griechenlands }\end{array}$ \\
\hline 58885 & Gesamtzahl gewaltsamer Todesfälle \\
\hline $\begin{array}{r}10226 \\
300 \\
200 \\
2000\end{array}$ & $\begin{array}{l}\text { Registrierte Uberlebende in Griechenland (Dez. 1945) } \\
\text { Nicht-Registrierte (geschätzter Mittelwert) } \\
\text { KZ-Überiebende: Direkt-Emigranten nach Palästina etc. } \\
\text { Flüchtlinge nach Nahost während der Okkupationszeit }\end{array}$ \\
\hline 12726 & Gesamtzahl der Uberlebenden \\
\hline 71611 & errechnete Zahl der Juden in Griechenland, Anfang 1941 \\
\hline
\end{tabular}

Wie bereits vermutet, ist also jener Zahl von $69591(67591+2000)$ "Israeliten“ eine nicht ganz unerhebliche Dunkelziffer hinzuzurechnen - wobei es sich weitgehend um Flüchtlinge aus dem deutschen Herrschaftsbereich handeln dürfte, oder auch um schon lānger in Griechenland ansässige Juden, die es in der gegebenen Situation vorziehen, auf die eine oder andere Art durch die Maschen des Zensus zu schlüpfen. Hinzu kommen einige Hundert getaufter Juden, insbesondere Sephardim, die leicht als solche zu identifizieren waren (sofern sie kein ,arischer" Ehepartner der Verfolgung entzog). Ein Teil der Dunkelziffer spiegelt möglicherweise in einzelnen Phasen noch einen - geringen - Geburtenzuwachs wider.

Die für 1945 genannte Zahl verringert sich in den nächsten Jahren erneut - infolge Auswanderung in die USA und andere Länder. Nur noch 8650 Juden leben in Griechenland ${ }^{154}$, als der Staat Israel gegründet wird und dort die Immigrationsbeschrānkungen fallen. Heute hat sich ihre Zahl bei etwa 6000 eingependelt, davon annähernd zwei Drittel in Athen, das zum neuen - wenn auch weit bescheideneren - Zentrum der griechischen Judenheit avanciert ist. Viele der isolierten Juden sind in die Hauptstadt abgewandert, wenige der Provinzgemeinden - wie vor allem Larisa - haben noch ein autonomes Eigenleben, die meisten besitzen nur noch eine Handvoll Mitglieder. Was indessen die alte Metropole Saloniki betriff, so leben zwar allein in Israel über 25000 Abkömmlinge (darunter auch Nachfahren früherer Auswanderungswellen) und in Tel Aviv wurde ein eigener Lehrstuhl für die Geschichte der Thessalonicher Sephardim eingerichtet; in der mazedonischen Hauptstadt selbst leben jedoch nur wenig mehr als 1000 Juden, und kaum einer der Jüngeren beherrscht noch Spaniolisch. ${ }^{155}$

153 Angesichts der widersprüchlichen Angaben bei einigen Transporten (insbesondere bei Nr. 20, vgl. Anm. 109) kann die Möglichkeit nicht ausgeschlossen werden, daß die Gesamtzahl bis maximal 200-300 zu vermindern ist.

154 Matarasso, Ki'omos, S. 57.

155 Zur heutigen Situation: Steven Bowman, Remnants and Memories in Greece, in: Forum (Jerusalem) 2 (1976) S. 63-71. - Der einfühlsame und informative Bericht von Kerstin Pudelko und Eberhard Rondholz (Die Sephardim am Weißen Turm - Erinnerungen an das jüdische Thessaloniki), in dem auch führende Vertreter der dortigen Gemeinde zu Wort kommen, liegt leider in keiner Druckfassung vor (gesendet im Westdeutschen Rundfunk, III. Programm, 11.6.1983). 
Griechenland ist zwar - den voreiligen Erfolgsmeldungen der SD-Strategen zum Trotz - nicht ,judenrein “ geworden, doch die Vielfalt und die Einmaligkeit seiner weit über 2000 Jahre alten jüdischen Kolonie ist in den Krematorien von Auschwitz und Treblinka unwiederbringlich in Rauch und Asche aufgegangen.

Deportation und Liquidierung der Juden Griechenlands (obne bulg. Zone)

\begin{tabular}{|c|c|c|c|c|c|c|c|}
\hline \multirow[t]{2}{*}{ O. $\mathbf{Z}$. } & \multirow[t]{2}{*}{ Herkunft } & \multirow{2}{*}{$\begin{array}{l}\text { Ankunft } \\
\text { A = Ausch- } \\
\text { witz } \\
\text { BB = Ber- } \\
\text { gen-Belsen }\end{array}$} & \multicolumn{3}{|c|}{$\begin{array}{l}\text { Zahl der Deportierten }{ }^{3} \\
\text { Schätzungen/Ermittlungen }\end{array}$} & \multirow{2}{*}{$\begin{array}{l}\text { Ins Lager eingelei- } \\
\text { tete } \\
\text { Männer / Frauen : } \\
\text { gesamt }\end{array}$} & \multirow{2}{*}{$\begin{array}{l}\text { Zahl4 } \\
\text { der } \\
\text { Verga- } \\
\text { sten }\end{array}$} \\
\hline & & & griech. $^{1}$ & $\begin{array}{l}\text { Unterlagen } \\
\text { Auschwitz }^{2}\end{array}$ & eigene & & \\
\hline 1 & Saloniki & A 20.3 .43 & 2400 & $(2800)$ & 2400 & $417 / 192: 609$ & 1791 \\
\hline 2 & Saloniki & A 24.3. & 2500 & $(2800)$ & 2500 & $584 / 230: 814$ & 1686 \\
\hline 3 & Saloniki & A 25.3 . & 2500 & 1901 & 2500 & $459 / 236: 695$ & 1805 \\
\hline 4 & Saloniki & A 30.3 . & 2800 & 2501 & 2501 & $312 / 141: 453$ & 2048 \\
\hline 5 & Saloniki & A 3.4 . & 2800 & 2800 & $3500^{5}$ & $334 / 258: 592$ & 2908 \\
\hline 6 & Saloniki & A 9.4 . & 2800 & 2500 & $2251^{6}$ & $318 / 161: 479$ & 1772 \\
\hline 7 & Saloniki & A 10.4 & $2800 / 2700$ & (2750) & 2750 & $537 / 246: 783$ & 1967 \\
\hline 8 & Saloniki & A 13.4 & 2800 & (2800) & 2800 & $500 / 364: 864$ & 1936 \\
\hline 9 & Saloniki & A 17.4 . & 2800 & $(3000)$ & 3000 & $467 / 262: 729$ & 2271 \\
\hline 10 & Saloniki & A 18.4 & 2800 & 2501 & 2501 & $360 / 245: 605$ & 1896 \\
\hline 11 & Saloniki & A 22.4 & 2800 & 2800 & 2800 & $255 / 413: 668$ & 2132 \\
\hline 12 & Saloniki & A 26.4 & 2800 & 2700 & 2700 & $445 / 193: 638$ & 2062 \\
\hline 13 & Saloniki & A 28.4 . & 2800 & 3070 & 3070 & $180 / 361: 541$ & 2529 \\
\hline 14 & Saloniki & A 4.5 . & 2600 & 2930 & 2930 & $220 / 318: 538$ & 2392 \\
\hline 15 & Saloniki & A $7 . / 8.5$ & 2600 & $\begin{array}{l}(1000)+ \\
2500^{7}\end{array}$ & 2600 & $568 / 68+247: 883$ & 1717 \\
\hline 16 & Saloniki & A 16.5 & 1700 & $(4500)$ & 1700 & $466 / 211: 677$ & 1023 \\
\hline 17 & Saloniki & A 8.6 & 820 & (880) & 820 & $220 / 88: 308$ & 512 \\
\hline 18 & Saloniki & BB 13.8 & 441 & - & 441 & 441 & $\cdots$ \\
\hline 19 & Saloniki & A 18.8 & 1800 & $(\mathbf{1 8 0 0 )}$ & $1800^{8}$ & $271 / \ldots: 271$ & 1529 \\
\hline \multirow[t]{2}{*}{20} & $\begin{array}{l}\text { Athen } \\
\text { (u.a.) }\end{array}$ & A 11.4 .44 & 5026 & $(1500)$ & $4645^{9}$ & $320^{10} / 113: 433$ & 4212 \\
\hline & & BB 16.4 . & 174 & $-\ldots$ & $155^{11}$ & 155 & --.- \\
\hline 21 & $\begin{array}{l}\text { Athen } \\
\text { (Korfu) }\end{array}$ & A 29./30.6. & 2375 & $(2000)$ & $2175^{12}$ & $446 / 131: 577$ & $1598^{13}$ \\
\hline \multirow[t]{3}{*}{22} & $\begin{array}{l}\text { Athen } \\
\text { (Rhodos) }\end{array}$ & A $16 . / 17.8$ & 1790 & $(2500)$ & 1846 & $346 / 254^{10}: 600$ & $1246^{14}$ \\
\hline & & & $\begin{array}{l}\text { A } 54111 \\
\text { BB } 615\end{array}$ & $(54533)$ & $\begin{array}{r}53789 \\
596\end{array}$ & $8025 / 4732: 12757^{10}$ & 41032 \\
\hline & & & 54726 & 54385 & & & \\
\hline
\end{tabular}

1 Die ersten 16 Transporte basieren auf Unterlagen der Griechischen Bahndirektion, die anderen auf den jeweils zuverlässigsten Quellen.

2 Danuta Crech, Deportation und Vernichtung der griechischen Juden im KL Auschwitz, in: Hefte von Auschwitz 11 (1970), S. 5-37, S. 24a (Tab. 2); die eingeklammerten Zahlen sind der Autorin zufolge sannahernde" Zahlen.

3 Basiert aul Czech, Deportation, Tab. 2.

4 Ebenda; es handelt sich um die Opfer der Erstselektion, eingerechnet sind ferner die auf dem Transport Verstorbenen.

5 Diese Ziffer scheint etwas hoch, doch existiert bei diesem Datum in der Aufstellung der Kontrollmarken eine Lücke in dieser Hōhe (Czech, Deportation, S. 22); zudem wäre in diesem Falle die Entsprechung zum Korherr-Bericht für das erste Quartal 1943 (13 435) sehr groß. Möglich ist allendings, daß einige Hundert für diesen Transport vorgesehene Juden aus Platzmangel einige Tage zurückgestellt wurden. Ein Teil der Kontrollmarken würde sich dann auf den nächsten Transport beziehen. 
6 Evtl. zu niedrig; vgl. Anm. 5).

7 Nach Ansicht des Vt. handelt es sich um einen Transport (und nicht um zwei), von dem einige Waggons mit Frauen noch am 7.5. ausgeladen wurden. Daher erscheint auch die hochgerechnete Zahl von 1000 als viel zu hoch, wohingegen sie für einen selbständigen Transport zu niedrig wäre.

8 Diese Zahl dürfte als gesichert gelten (u a Michael Molho, In Memoriam. Hommage aux victimes juives des nazis en Grèce. Bd. I, Saloniki 1948, S. 94). Eindeutig zu hoch (2500) bzw. zu niedrig (1200) sind die Schätzungen von I. A. Matarasso, Ki'omos oloi tous den pethanan, Athen 1948, S. 55, bzw. Cecil Roth, The Last Days of Jewish Selonica, in: Commentary X: 1 (Juli 1950), S. S5.

9 Vgl. Anm. 109; zu Graevenitz" Angabe von (insgesamt) 4700 wurde eine "Sicherheitsmarge" von 100 ad. diert.

10 Nach neuesten Unterlagen zu niedrig, s. Anm. 140.

11 Vgl. Anm. 110

12 Nehama (Israilitiki Koinotis Thessalonikis, In Memoriam, Saloniki 1976, S. 246) nennt 1800 Korfioten sowie 575 in Athen seit April verhaftete Juden. Die zweite Teilsumme ist nach der Quellenlage unwahrscheinlich und wurde daher um 200 vermindert. Damit erfolgt eine Annäherung an die Auschwitzer Zahl (2000) und die der deutschen Gesandtschaft ( Elladi 1941-1944, Athen 1969, S. 17.

13 Dr. Wolkens Zahl 1423 allein für die vergasten Männer (Filip Friedman, This was Oswiecim, London 1946, S. 25) kann unmöglich stimmen.

14 Auch hier ist Wolkens Angabe (1202) unkorrekt, da sie die Verluste der Frauen minimalisieren würde. Evil. liegt eine Verwechslung mit dem nächsten Transport (aus Lodz) vor, bei dem W. wieder 1202 vergaste Männer notiert. Vgl. dagegen den Beitrag zu Italien in diesem Band, Tabelle 6, in der die Gesamtzahl der von Rhodos und Kos Deportierten 1641 betrigt. 